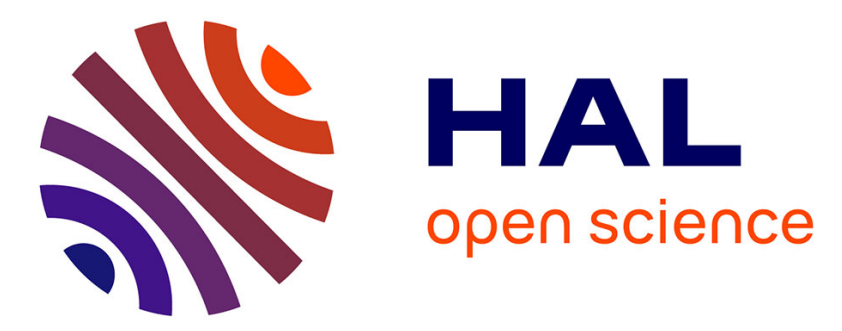

\title{
Building Ab Initio Interface Pourbaix diagrams to Investigate Electrolyte Stability in the Electrochemical Double Layer: Application to Magnesium Batteries
} Anja Kopač Lautar, Jan Bitenc, Robert Dominko, Jean-Sébastien Filhol

\section{- To cite this version:}

Anja Kopač Lautar, Jan Bitenc, Robert Dominko, Jean-Sébastien Filhol. Building Ab Initio Interface Pourbaix diagrams to Investigate Electrolyte Stability in the Electrochemical Double Layer: Application to Magnesium Batteries. ACS Applied Materials \& Interfaces, 2021, 13 (7), pp.8263-8273. 10.1021/acsami.0c19579 . hal-03150793

\section{HAL Id: hal-03150793 \\ https://hal.science/hal-03150793}

Submitted on 24 Feb 2021

HAL is a multi-disciplinary open access archive for the deposit and dissemination of scientific research documents, whether they are published or not. The documents may come from teaching and research institutions in France or abroad, or from public or private research centers.
L'archive ouverte pluridisciplinaire HAL, est destinée au dépôt et à la diffusion de documents scientifiques de niveau recherche, publiés ou non, émanant des établissements d'enseignement et de recherche français ou étrangers, des laboratoires publics ou privés. 


\title{
Building $a b$ initio interface Pourbaix diagrams to investigate electrolyte stability in the electrochemical double layer: application to Magnesium batteries
}

\author{
Anja Kopač Lautar ${ }^{a}$, Jan Bitenc ${ }^{a}$, Robert Dominko ${ }^{a, b, c}$, Jean-Sébastien Filhol ${ }^{*}$ d,e \\ ${ }^{a}$ Department of Materials Chemistry, National Institute of Chemistry, Slovenia \\ ${ }^{b}$ Faculty of Chemistry and Chemical Technology, University of Ljubljana, Slovenia \\ ${ }^{c}$ ALISTORE-ERI, FR3104, 80039 Amiens cedex, France \\ ${ }^{d}$ Institut Charles Gerhardt, CNRS \& Université de Montpellier, Place E. Bataillon, France \\ ${ }^{e} R S 2 E$ French network on Electrochemical Energy Storage, FR5439, Amiens, France \\ *Corresponding author: Jean-Sébastien Filhol (jean-sebastien.filhol@umontpellier.fr)
}

\begin{abstract}
Insights into the electrochemical processes occurring at the electrode-electrolyte interface are a crucial step in most electrochemistry domains and in particular in the optimization of the battery technology. However, studying potential dependent processes at the interface is one of the biggest challenges, both for theoreticians and experimentalists. The challenge is pushed further when stable species also depend on the concentration of specific ligands in the electrolyte, such as chlorides. Herein we present a general theoretical ab initio methodology to compute Pourbaix-like diagram of complex electrolytes as a function of electrode potential and anion's chemical potential, i.e. concentration. This approach is not only developed for the bulk properties of the electrolytes, but also for electrode-electrolyte interfaces. In the case of chlorinated magnesium complexes in dimethyl ether, we show that the stability domains of the different species are strongly shifted at the interface compared to the bulk of the electrolyte due to the strong local electric fields and charges occurring in the double layer. Thus, as the interfacial stability domains are strongly modified, this approach is necessary to investigate all interface properties that often govern reaction's kinetics, such as solvent degradation at the electrode. Interface Pourbaix diagram is used to give some insight into the improved stability at the $\mathrm{Mg}$ anode induced by the addition of chloride. Due to its far-reaching insights, transferability and wide applicability, the methodology presented herein should serve as a valuable tool not only for the battery community but also for the wider electrochemical one.
\end{abstract}


Keywords: interface, electrochemistry, Pourbaix diagram, electrolyte, Magnesium battery, chloride, Density Functional Theory, grand canonical.

\section{Table of Content Graphics}

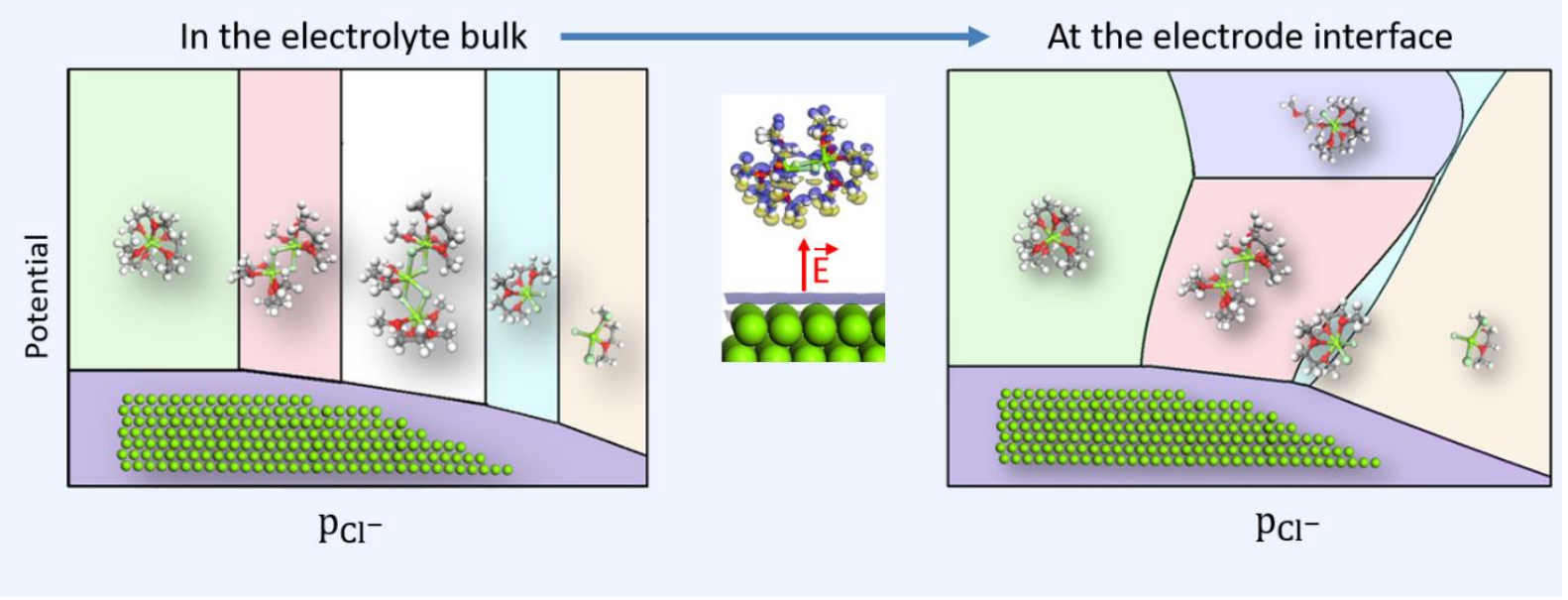

\section{Introduction}

Pourbaix diagram is one of the most classical tools to investigate electrochemical stability. It allows a quick determination of possible stable phases for a given potential as a function of $\mathrm{pH}$ or a ligand chemical potential. It gives a representation of a system's thermodynamic equilibrium redox properties and it is classically used in all fields of electrochemistry ranging from the energy conversion to corrosion. Although they were initially built from experimental data, Pourbaix diagrams can also be constructed from ab initio calculations. ${ }^{1}$ However, this remains particularly challenging in solution as it requires computing ionic species with different oxidation numbers, solvent coordination, electrostatic interactions and entropic contributions. Nevertheless, Pourbaix diagrams are built for the bulk of a solution and it is not clear whether they give a proper description of the stability of species close to an electrode surface, in particular, for the electrochemical double layer. Indeed, the energetics of the different species in the double layer, where the local electric field is of the order of $1-10 \times 10^{6}$ V.cm ${ }^{-1}$ are strongly impacted by the surface-electrolyte interactions: the electroactive species in the double layer can be different from those observed in the electrolyte bulk. ${ }^{2,3}$ This is even more important given that these electroactive species present in the double layer are the ones undergoing 
the electrochemical reactions for many electrochemical systems. Thus, the stability change at the interface should be thoroughly investigated and summarized in a specific interface Pourbaix diagram.

A particularly interesting test case is the magnesium electrode as magnesium metal batteries are considered promising candidates for high-density energy storage due to high volumetric capacity, low cost, and safety. ${ }^{4-11}$ Electrolyte of choice for $\mathrm{Mg}$ batteries are ethereal solvents, with $\mathrm{Mg}(\mathrm{TFSI})_{2}$ (TFSI $=$ bis(trifluoromethanesulfonyl)imide) and $\mathrm{MgCl}_{2}$ salt as an additive. The inclusion of $\mathrm{MgCl}_{2}$ salt is critical, as it improves the stripping and deposition properties, whereas the electrochemical performance of $\mathrm{Mg}$ anode in a system with an electrolyte consisting only of $\mathrm{MgTFSI}_{2}$ salt is poor. ${ }^{11-18}$ Furthermore, it has been experimentally shown that chlorides affect the active cation species inducing the formation of $\mathrm{Mg}_{\mathrm{x}} \mathrm{Cl}_{\mathrm{y}}{ }^{(2 \mathrm{x}-\mathrm{y})+}$ complexes, which presumably play a crucial role in the improvement of the full cell performance ${ }^{14,16-18}$ Nevertheless, the exact reason for this improvement is still not clear, thus making Mg-interfaces a highly interesting test case. More efforts were taken to understand the interplay of $\mathrm{Al}$ and $\mathrm{Mg}$ speciation in so-called MACC electrolytes which are prepared by dissolving $\mathrm{MgCl}_{2}$ and $\mathrm{AlCl}_{3}$ in the THF. A formation of $\left[\mathrm{Mg}_{2}(\mu-\mathrm{Cl})_{3} \cdot 6 \mathrm{THF}\right]^{+}$complex enables reversible stripping and deposition process, while chloride anions that remain in the electrolyte after conditioning and aluminum cation reduction enhance $\mathrm{Mg}$ deposition. ${ }^{19,20}$

To understand the role of chloride in these systems, it is first crucial to investigate the different molecular species involved in the bulk of the electrolyte and study their stability as a function of electrode potential and $\mathrm{Cl}^{-}$chemical potential by building the corresponding Pourbaix diagram. Because of the strong electric effect within the double layer at the electrode interface, the active electrochemical species can be different at the interface from those in the electrolyte bulk: it is thus necessary to identify the double layer stable species as a function of the local conditions (potential and $\mathrm{Cl}^{-}$chemical potential), and build the corresponding interface Pourbaix diagram. This approach can be of great help to understand any electrochemical system but still remains a challenge for theoretical calculations. To tackle this challenge, we use a methodology previously developed in our group to include the electrochemical effects. ${ }^{2,21-26}$

In the present study, we first compute different $\mathrm{Mg}_{\mathrm{x}} \mathrm{Cl}_{\mathrm{y}}{ }^{(2 \mathrm{x}-\mathrm{y})+}$ complexes in the low dielectric constant DME solvent, using a DFT approach. Then, we build the associated Pourbaix diagram for the bulk electrolyte as a function of the electrode potential and $\mathrm{Cl}^{-}$chemical potential: this computed diagram is fully consistent with the experimental observations. Then, we use a grand canonical approach to model electrochemical interface energies as a function of $\mathrm{Cl}^{-}$chemical potential. This enables building the Pourbaix diagram of $\mathrm{Mg}$-species within the double layer. We observe and explain 
how the phase diagram at the interface is strongly modified in comparison to the one at the bulk due to electrochemical effects. At identical potential/chemical potential conditions, the stable specie in the interface can differ from the one in the bulk, giving confirmation of interface specific behavior. Finally, we show that bulk and interfacial Pourbaix diagrams can be used as tools to comprehend the deactivation of the electrophilic behavior of $\mathrm{Mg}_{\mathrm{x}} \mathrm{Cl}_{\mathrm{y}}{ }^{(2 \mathrm{x}-\mathrm{y})+}$ by a chloride preventing DME solvent degradation that is highly detrimental to the battery. The methodology presented herein is transferable to other electrolyte compositions, as well as to any electrochemical interfaces such as the ones found in catalysis and corrosion.

\section{Computational Details}

Periodic DFT calculations were performed using the Vienna Ab Initio Simulation Package (VASP) 27,28 within the generalized gradient approximation (GGA) using $\mathrm{PBE}^{29}$ functional for exchange and correlation potential and projector augmented wave pseudopotentials (PAW) ${ }^{30}$ with a cut-off energy of $450 \mathrm{eV}$. When modelling interface, long-range electrostatic interactions through space arising from periodic boundary conditions were avoided by building a symmetric unit cell. The electrode surfaces were modelled with a 5-layer symmetric slab of $\mathrm{Mg}(0001)$ surface in a $(5 \times 5)$ supercell. One Mgcomplex including explicit solvent molecules was added symmetrically at each side of the slab (Figs. S2a, S2b). This ensured a homogeneous charging of both sides of the slab for the electrochemical calculations to coherently extract the energetic of the charge interfaces (Fig. S2c). The inter-slab distance between periodic surfaces was set to $40 \AA$. The effective Mg-complex concentration is then set to $0.33 \mathrm{~mol} . \mathrm{L}^{-1}$. An implicit solvent was added in the inter-slab space by means of a Polarizable Continuum Model (PCM) as provided by VASPSOL. ${ }^{31,32}$ The PCM is parameterized with the solvent dielectric constant (i.e. DME $\boldsymbol{\varepsilon}_{\boldsymbol{r}}=\mathbf{7 . 2 0}$ ) and the cavity size defined by an electronic density cut-off parameter. The density cut-off parameter was determined as $2.5 \times 10^{-5}$ for the studied systems. This implicit solvation associated with an explicit solvation for the first solvation shell of cation' was shown to give reasonable results for different redox processes, ${ }^{21,25,33}$ including $\mathrm{Mg}^{\prime \prime}$ reduction and $\mathrm{Mg}$ electrocapillarity curves. ${ }^{34}$ The Brillouin zone integration in k-space was performed on a $4 \times 4 \times 1 \mathrm{k}$ point grid. Structural relaxation was performed on all atoms except the central Mg-slab layer, which was kept frozen to bulk parameters. The surface potential in vacuum scale $\left(V_{\text {vacuum }}\right)$ is directly extracted from the calculation but can be converted into the SHE scale $\left(V_{S H E}\right)$ by using: $V_{S H E}=$ $V_{\text {vacuum }}-4.5^{35,36}$ or the $\mathrm{Mg}^{2+} / \mathrm{Mg}$ scale by using $V_{M g}=V_{\text {vacuum }}-2.1$. When modelling bulk electrolyte, the calculation for the specie of interest was done by adding the specie in a unit cell of dimensions ranging from $12 \times 12 \times 12 \AA^{3}$ up to $60 \times 60 \times 60 \AA$ (depending on the dimensions of the species 
and the modelled concentration) in implicit solvation. In this case, the k-space integration was performed at $\Gamma$-point. In all calculations the residual forces after structural relaxation were lower than $0.01 \mathrm{eV} / \AA ̊$.

The interface electrochemical effects are computed through surface charging and calculation of interface free electrochemical energy $\gamma$ by means of a Grand canonical ensemble approach as details in the Supporting information $\mathbf{S 2}$ and in ref[22]. The free electrochemical energy $\gamma$ was computed for each interface as a function of the applied potential (see Supporting Information Fig. S1 and section S7). It has a typical inverted parabola shape and can be used to compute the interface Pourbaix diagram (vide infra).

\section{Theoretical approach}

It is important to note that the ligand chemical potential is typically determined through $\mathrm{pH}$, thus the well-known Pourbaix diagram, referred in further text as classical Pourbaix diagram, is the electrode potential vs. $\mathrm{pH}$ diagram. Herein we use a more general definition where the ligand chemical potential is defined relatively to the ligand by the relation $\mu=\mu^{0}+R T \ln a_{C l}$-with $\mu^{0}$ the reference chemical potential and $a_{C l^{-}}$the chloride activity. In this sense, the diagram we refer to is not strictly the most typical Pourbaix diagram. However, as it is merely a more general case, we keep the terminology. All calculations were performed using the periodic DFT method neglecting finite temperature effects. This approximation is not expected to change the shape of the Pourbaix diagram as the change of energy induced by electrochemical effects are larger than the finite temperature contributions in the present case. Nevertheless, improvements can be achieved by including vibrational finite temperature contributions and including some extended Debye-Hückel models to account for part of the configuration entropy and activity coefficients. ${ }^{20}$

\section{1. $\quad \operatorname{Mg}_{\mathrm{x}} \mathrm{Cl}_{\mathrm{y}} \mathrm{DME}_{\mathrm{z}}^{(2 x-y)+}$ complexes.}

Experimentally, these complexes are formed by mixing $\mathrm{Mg}(\mathrm{TFSI})_{2}$ and $\mathrm{MgCl}_{2}$ salts. Experimental and theoretical results suggest that TFSI ${ }^{-}$anions are not in the first solvation shell, but are positioned at a relatively large distance, approximately $6 \AA$ from $\mathrm{Mg}$ cation. ${ }^{11,13,14,17,37-39}$ Thus, we have computed explicit models for the first solvation shell for $\mathrm{Mg}_{\mathrm{x}} \mathrm{Cl}_{\mathrm{y}} \mathrm{DME}_{\mathrm{z}}(2 x-y)+$ complexes and polarizable continuum model (PCM) for the rest. Such an approach was shown to lead to a quantitative computation of the Redox properties. ${ }^{21,25,33,34}$ The following species were computed: $\operatorname{Mg}(\mathrm{DME})_{3}{ }^{2+}$, $\operatorname{MgCl}(\mathrm{DME})_{3}{ }^{+}, \mathrm{Mg}_{2} \mathrm{Cl}_{2}(\mathrm{DME})_{4}{ }^{2+}, \mathrm{Mg}_{3} \mathrm{Cl}_{4}(\mathrm{DME})_{5}{ }^{2+}, \mathrm{MgCl}_{2}$ (DME) $)_{2}$, and $\mathrm{MgCl}_{3}$ (DME) ${ }^{-}$(Fig. 1). All 
these species, except $\mathrm{MgCl}_{3}(\mathrm{DME})^{-}$, have a coordination number of 6 . This is in agreement with previously reported $\mathrm{Mg}^{2+}$ local bonding. ${ }^{16,21,40-44}$ The exception is $\mathrm{MgCl}_{3} \mathrm{DME}^{-}$with a coordination number 4 . In this case, a higher Mg-coordination cannot be reached since the initial structure $\mathrm{MgCl}_{3}(\mathrm{DME})_{2}{ }^{-}$relaxes into $\mathrm{MgCl}_{3} \mathrm{DME}^{-}$and one $\mathrm{DME}$ in the second solvation shell as shown by calculations. Only one of the two oxygen atoms of the DME in the first solvation shell remains attached to the $\mathrm{Mg}$ atom leading to a local tetrahedral geometry. This can be explained by the negative charge of the $\mathrm{MgCl}_{3}^{-}$species: the electron enriched $\mathrm{Mg}$-species change their energetically favored coordination number and begins following octet rule. It is not clear if a $\mathrm{Mg}(\mathrm{TFSI})_{2} / \mathrm{MgCl}_{2}$ mixture can experimentally reach a chemical potential high enough to produce $\mathrm{MgCl}_{3}(\mathrm{DME})^{-}$. Thus, $\mathrm{MgCl}_{3}(\mathrm{DME})^{-}$-remains hypothetical in a pure DME solvent. Nevertheless, $\mathrm{MgCl}_{3}(\mathrm{DME})^{-}$was found in $\mathrm{MgCl}_{2} / \mathrm{AlCl}_{3}$ in DME electrolyte mixture. ${ }^{16}$ Furthermore, an equivalent $\mathrm{MgCl}_{3}$ (THF) ${ }^{-}$complex was experimentally synthesized in the ethereal solvent THF and was found to have a similar tetrahedral structure as the one computed for $\mathrm{MgCl}_{3}(\mathrm{DME})^{-} .45,46$

The $\mathrm{MgCl}_{2}(\mathrm{DME})_{2}$ presents a cis/trans isomer. Calculations have shown that the cis-isomer is more stable than the trans-isomer by about $30 \mathrm{meV}$, in agreement with experimental observations. ${ }^{14} \mathrm{We}$ only consider the cis-isomer in the following calculations. All these structures are in agreement with previous calculations and experimental structures. ${ }^{14,16,39,47-49}$

a)

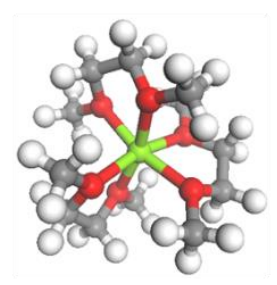

d)

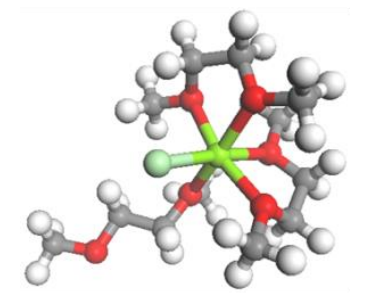

b)

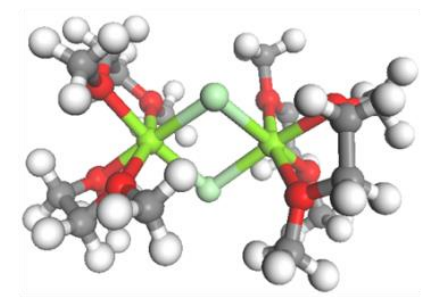

c)

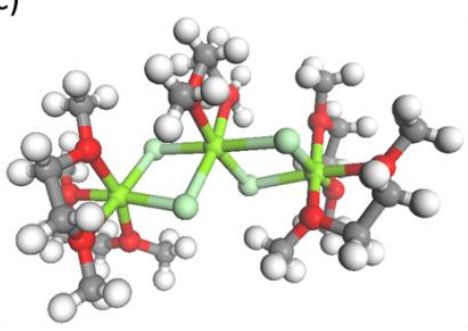

e)

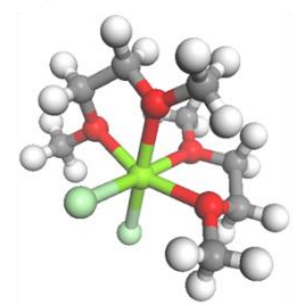

f)

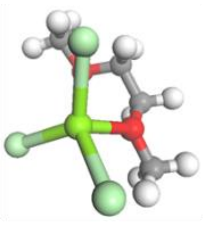

$\begin{array}{lllllllllll}\mathrm{Mg} & \mathrm{Cl} & \mathrm{O} & \mathrm{C} & \mathrm{H}\end{array}$

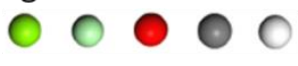

Figure 1. Various active cation species of Mg-complexes used in DFT calculations (only the most stable are presented). (a) $\mathrm{Mg}(D M E)_{3}{ }^{2+}$, (b) $\mathrm{Mg}_{2} \mathrm{Cl}_{2}(\mathrm{DME})_{4}{ }^{2+}$, (c) $\mathrm{Mg}_{3} \mathrm{Cl}_{4}(\mathrm{DME})_{5}{ }^{2+}$, (d) $\mathrm{MgCl}(\mathrm{DME})_{3}{ }^{+}$, (e) $\mathrm{MgCl}_{2}(\mathrm{DME})_{2}$, and (f) $\mathrm{MgCl}_{3} \mathrm{DME}$. All these species have a coordination number of 6 , except $\mathrm{MgCl}_{3} \mathrm{DME} \mathrm{E}^{-}$with coordination number 4. 


\subsection{Building Pourbaix diagram}

To rationalize the different structure stability, we have constructed the electrochemical potential/ $\mathrm{Cl}^{-}$ chemical potential Pourbaix diagram. Rather than the classical pH dependence, we used the chloride chemical potential as the variable, which can also be related to the concentration of chloride $\left[\mathrm{Cl}^{-}\right]$in the solution by expressing the chloride activity $a_{C l^{-}}$to give $\mu_{C l^{-}}=\mu_{C l^{-}}^{0}+R T \ln \left(\gamma_{C l^{-}}\left[\mathrm{Cl}^{-}\right]\right)$, with $\gamma_{C l^{-}}$ the activity coefficient of $\mathrm{Cl}^{-}$. The diagram is built both for the bulk of the electrolyte, as well as for the electrolyte/Mg anode interface. We first introduce steps for building the bulk diagram before moving to a more complex interfacial diagram. For the following diagrams, we consider that the total " $\mathrm{Mg}$ " concentration is constant: this approximation does not change the global shape of the diagrams.

\subsubsection{Bulk electrolyte Pourbaix diagram}

In the bulk, the Pourbaix approach is based on two types of reactions: (i) the non-electrochemical reactions (dimerization, complexation...) that are related to the exchange of a $\mathrm{Cl}^{-}$anion (i.e. depend on the concentration or chemical potential of $\mathrm{Cl}^{-}$), and (ii) the electrochemical reactions that are related to exchange of electrons (i.e. are potential dependent).

\section{Non-electrochemical reaction}

The non-electrochemical reactions can be decomposed into two types. The first type is associated with an equilibrium not implying an explicit exchange of $\mathrm{Cl}^{-}$in the associated chemical equation (e.g. a dimerization equilibrium):

$2 \mathrm{MgCl}(\mathrm{DME})_{3}^{+} \rightleftarrows \mathrm{Mg}_{2} \mathrm{Cl}_{2}(\mathrm{DME})_{4}^{2+}+2 \mathrm{DME}$

In this case, neither electron nor $\mathrm{Cl}^{-}$are exchanged. Thus, the corresponding equilibrium depends neither on the electrode potential nor on the $\mathrm{Cl}^{-}$chemical potential. Therefore, only one of the two species can exist in the diagram (e.g. the most stable between $\mathrm{MgCl}(\mathrm{DME})_{3}^{+}$or $\mathrm{Mg}_{2} \mathrm{Cl}_{2}(\mathrm{DME})_{4}^{2+}$ ). In the present case, calculations show that the dimeric specie $\mathrm{Mg}_{2} \mathrm{Cl}_{2}(\mathrm{DME})_{4}^{2+}$ is the most stable one.

The second type of non-electrochemical reactions are the ones involving explicit $\mathrm{Cl}^{-}$exchange such as:

$\mathrm{Mg}(\mathrm{DME})_{3}^{2+}+\mathrm{Cl}^{-} \rightleftarrows \frac{1}{2} \mathrm{Mg}_{2} \mathrm{Cl}_{2}(\mathrm{DME})_{4}^{2+}+\mathrm{DME}$

In this case, the $\mathrm{Cl}^{-}$chemical potential frontier between $\mathrm{Mg}(\mathrm{DME})_{3}^{2+}$ and $\mathrm{Mg}_{2} \mathrm{Cl}_{2}(\mathrm{DME})_{4}^{2+}$ in chemical equilibrium is given by a vertical line independent of the potential. The vertical frontier is given by: 


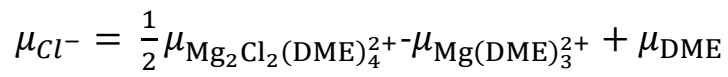

This approach is extended to all the other considered equilibria that are given in Supporting Information (S2).

\section{Electrochemical reaction}

A purely redox process to form $\mathrm{Mg}$ bulk metal (stated as simply " $\mathrm{Mg}$ ") not necessitating $\mathrm{Cl}^{-}$exchange is:

$\mathrm{Mg}(\mathrm{DME})_{3}^{2+}+2 e^{-} \rightleftarrows \mathrm{Mg}+3 \mathrm{DME}$

The associated frontier between $\operatorname{Mg}(\mathrm{DME})_{3}^{2+}$ and $\mathrm{Mg}$ metal at the electrochemical equilibrium is independent of the $\mathrm{Cl}^{-}$chemical potential. It is thus associated with a horizontal line (Fig. 2) given by:

$\mu_{\mathrm{Mg}(\mathrm{DME})_{3}^{2+}}-2 F V_{\mathrm{Mg}^{2+} / \mathrm{Mg}}=\mu_{\mathrm{Mg}}+3 \mu_{\mathrm{DME}}$

Note that Eq. $\mathbf{5}$ is fully equivalent to the Nernst relation:

$V_{M g^{2+} / M g}=-\frac{\mu_{\mathrm{Mg}}+3 \mu_{\mathrm{DME}}-\mu_{\mathrm{Mg}(\mathrm{DME})_{3}^{2+}}}{2 F}$

In the general case, electron exchange can be coupled with $\mathrm{Cl}^{-}$exchange, so that species are in chemical and electrochemical equilibrium. An example of such a case is:

$\mathrm{MgCl}_{2}(\mathrm{DME})_{2}+2 e^{-} \rightleftarrows \mathrm{Mg}+2 \mathrm{DME}+2 \mathrm{Cl}^{-}$

The equilibrium potential frontier between the two redox domains is a line given by:

$V_{\mathrm{Mg}^{2+} / \mathrm{Mg}}=-\frac{\mu_{\mathrm{Mg}}+2 \mu_{\mathrm{DME}}-\mu_{\mathrm{MgCl} l_{2}(\mathrm{DME})_{2}}+2 \mu_{C l^{-}}}{2 \mathrm{~F}}$

The associated slope for this frontier is given by $\frac{\Delta n_{C l^{-}}}{\Delta n_{e^{-}}}$, with $\Delta n_{C l^{-}}$the number of exchange chloride and $\Delta n_{e^{-}}$the number of exchanged electrons. The full set of equations is given in the SI (S2).

\section{Computing the diagram}

All frontier lines of the Pourbaix diagram can be obtained from the energetics of the different species. Nevertheless, when using a low dielectric constant solvent, the infinite dilution limit that can be easily extracted from molecular calculations is not a good representation for ionic species of experiments in the 1-0.1 mol. $\mathrm{L}^{-1}$ range. Indeed, we have chosen to investigate different unit cell parameters for a PCM-crystals constituted of $1 \mathrm{Mg}_{\mathrm{x}} \mathrm{Cl}_{\mathrm{y}}(\mathrm{DME})_{\mathrm{z}}^{(2 \mathrm{x}-\mathrm{y})+}$ complex with $(2 \mathrm{x}-\mathrm{y})$ monocharged atomic counter 
ions in a cubic unit cell. The cell is filled with a Polarizable Continuum Model (PCM) with a dielectric constant $\varepsilon_{r}=7.2$. The energy of the obtained PCM crystal for $\left(\operatorname{MgCl}(\mathrm{DME})_{3}^{+}, \mathrm{Cl}^{-}\right)$as a function of the inverse of the unit cell parameter is linear (S3, Fig. S3). The extrapolation of the line for $1 / r \rightarrow 0$ gives the energy for the infinite dilution limit of the ion pair (i.e. without electrostatic interaction). In the case of DME, the electrostatic interaction energies are hundreds of meV larger for the concentrated solutions compared to the infinite dilution limit. Thus, the Pourbaix diagram in a non-aqueous electrolyte with low $\varepsilon_{r}$ should include the strong change in enthalpy due to the electrostatic contributions. This can be simply estimated within the proposed model by using the energy dependency computed from the PCM-crystal model. This allows us to obtain a reasonable description of the system's electrostatic interactions. Therefore, we have computed the energetic of all $\mathrm{Mg}$ species, for infinite dilution and in a more realistic case for battery applications corresponding to a total "Mg" -concentration of $0.4 \mathrm{M}$.

Using the equations given in the previous section, the corresponding frontier lines were computed. All frontiers between metastable species were removed following the classical Pourbaix construction. The corresponding phase diagrams for infinite dilution and $0.4 \mathrm{~mol} . \mathrm{L}^{-1}$ concentration are given respectively in Fig. 2 and in Fig. S4. Despite different concentrations, the different domains behave similarly. The differences are discussed in the Supporting Information (S4, Fig. S4) and we keep the 0.4 mol.. $\mathrm{L}^{-1}$ diagram in further discussions.

In this bulk Pourbaix diagram, all studied species present a stability domain except $\mathrm{MgCl}(\mathrm{DME})_{3}^{+}$. The monomeric cation $\mathrm{MgCl}(\mathrm{DME})_{3}^{+}$is not present due to the larger stability of the dimeric specie $\mathrm{Mg}_{2} \mathrm{Cl}_{2}(\mathrm{DME})_{4}^{2+}$. The equilibrium potential for the $\mathrm{Mg}(\mathrm{DME})_{3}^{2+} / \mathrm{Mg}$ redox pair is found to be $0 \mathrm{~V} / \mathrm{Mg}(-2.4 \mathrm{~V} / \mathrm{SHE})$, in agreement with the experimental value and previous calculations. ${ }^{21,50}$ With increasing chloride chemical potential, $\operatorname{Mg}(\mathrm{DME})_{3}^{2+}$ is converted into more and more chlorinated species: $\mathrm{Mg}_{2} \mathrm{Cl}_{2}(\mathrm{DME})_{4}{ }^{2+}, \mathrm{Mg}_{3} \mathrm{Cl}_{4}(\mathrm{DME})_{5}{ }^{2+}, \mathrm{MgCl}_{2}(\mathrm{DME})_{2}$, and $\mathrm{MgCl}_{3} \mathrm{DME}^{-}$. Note that for the 0.4 mol. $\mathrm{L}^{-1}$, our calculations are not precise enough to discriminate between the stability of the neutral molecular crystal and neutral solvated specie of $\mathrm{MgCl}_{2}(\mathrm{DME})_{2}$ : both forms should remain energetically close. Finally, the high oxidation limit of the diagram is given by the $\mathrm{Cl}_{2} / \mathrm{Cl}^{-}$redox pair with a potential between 4.15 and $2.9 \mathrm{~V} / \mathrm{Mg}(1.75$ and $0.5 \mathrm{~V} / \mathrm{SHE})$, depending on the $\mathrm{Cl}^{-}$chemical potential). 


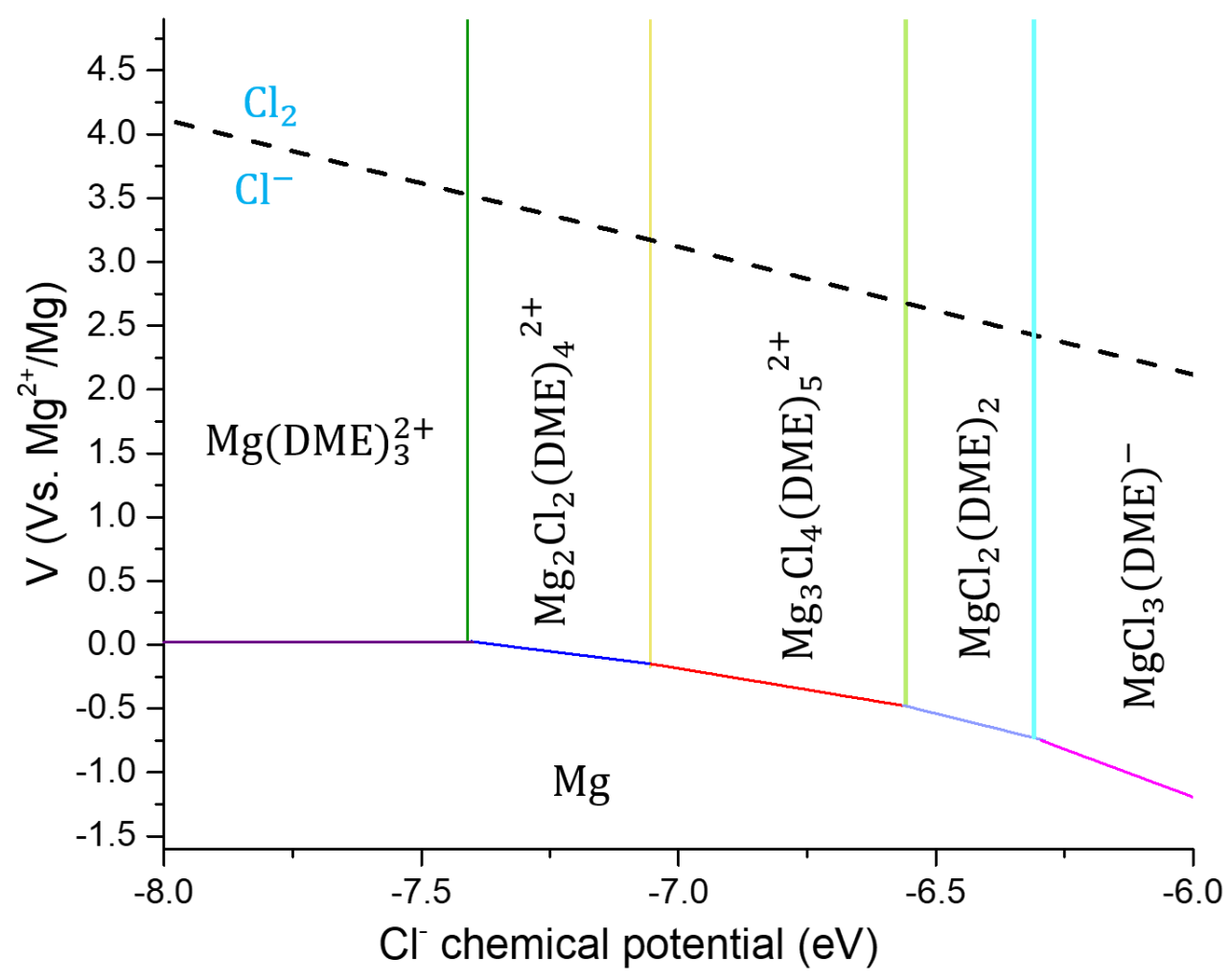

Figure 2: Pourbaix diagram for the bulk of the electrolyte at a concentration of $C=0.4$ mol. $L^{-1}$. The vertical lines are independent of potential and define frontiers between species in chemical equilibrium. The horizontal lines are independent of the $\mathrm{Cl}^{-}$chemical potential (species are in electrochemical equilibrium). Generally, electron and $\mathrm{Cl}^{-}$exchange is coupled (species are in chemical and electrochemical equilibrium) which results in sloped lines. The potential scale is referred to $\mathrm{Mg}^{2+} / \mathrm{Mg}$ redox pair.

\subsubsection{Interface Pourbaix diagram}

The stability of Mg-complexes at the Mg interface within the electrochemical double layer is strongly modified compared to the bulk of the electrolyte by the presence of strong electric fields, electric charge image between the ions and the surface, and eventually charge transfers. Thus, in the electrochemical interface case, a specific approach in building Pourbaix diagram is needed to account for these effects. 
The Pourbaix diagram of the species in the double layer is quite different from the one of a typical bulk diagram as presented above. The main difference arises from the strong interactions of the different magnesium complexes with the surface electric field and potential, blurring the electrochemical/nonelectrochemical differences. At the interface, the amount of electron exchange is not strictly an integer value, as the thermodynamic condition of potential equilibrium also implies a fraction of electron to achieve it. ${ }^{22} \mathrm{~A}$ detailed example is given in $\mathrm{S} 1$ section and in the Fig. S1 of the Supporting Information. For the description of the interface at a potential $V$ with an excess of electron $n_{e^{-}}$, we use a surface free electrochemical energy $\gamma$ associated with a grand canonical ensemble, rather than the chemical potential $\mu$ associated with the canonical approach used for the construction of the bulk electrolytes diagram. $\gamma(V)$ is defined as:

$$
\gamma_{\mathbb{E}}(V)=\mu_{\mathbb{E}}(V)-n_{e^{-}} \mu_{e^{-}}=\mu_{\mathbb{E}}(V)+n_{e^{-}} F V
$$

with $F$ the Faraday constant and $\mu_{\mathbb{E}}$ the charged surface energy at a potential $V .{ }^{22}$ Free electrochemical energies are computed following the approach described in details in previous works. ${ }^{21,22,25}$

The methodology for obtaining an interface Pourbaix diagram is similar to the one for the bulk, with the main difference being that the stability of various species at the interface, and consequently their free electrochemical energies, are potential dependent. We will use in this section the same distinction of electrochemical vs. non-electrochemical reactions, even if it is not as relevant.

\section{Non electrochemical reaction}

Since each molecular specie is in interaction with the electrode surface $\mathbb{E}$ at specific potential $V$, a specific potential dependency must be considered. For example, the dimerization equilibrium, not involving chloride, at the interface is given by Eq. 9:

$2 \mathrm{MgCl}(\mathrm{DME})_{3}^{+} / \mathbb{E}(V) \rightleftarrows \mathrm{Mg}_{2} \mathrm{Cl}_{2}(\mathrm{DME})_{4}^{2+} / \mathbb{E}(V)+\emptyset / \mathbb{E}(V)+2 \mathrm{DME}$

Where " $/ \mathbb{E}(V)$ " is used to denote that the specie is at the interface and is interacting with the surface $\mathbb{E}$. Consistently with the bulk approach, we use a constant total number of magnesium atom in the complexes at the double layer: therefore the creation of the dimer at the interface (" $\mathrm{Mg}_{2} \mathrm{Cl}_{2}(\mathrm{DME})_{4}^{2+} /$ $\mathbb{E}(V)$ ") from two monomers (" $\mathrm{MgCl}(\mathrm{DME})_{3}^{+} / \mathbb{E}(V)$ ") also produces a bare $\mathrm{Mg}$-surface referred to as “

The free electrochemical formation energy $\Delta \gamma_{\text {dimer }}$ of the dimer is:

$$
\Delta \gamma_{\text {dimer }}(\mathrm{V})=\gamma_{\mathrm{Mg}_{2} \mathrm{Cl}_{2}(\mathrm{DME})_{4}^{2+} / \mathbb{E}(\mathrm{V})}(\mathrm{V})+\gamma_{\varnothing / \mathbb{E}(\mathrm{V})}(\mathrm{V})+2 \mu_{\mathrm{DME}}-2 \gamma_{\mathrm{MgCl}(\mathrm{DME})_{3}^{+} / \mathbb{E}(\mathrm{V})}
$$


$\Delta \gamma_{\text {dimer }}(V)$ is a potential dependent quantity that can be positive or negative depending on the value

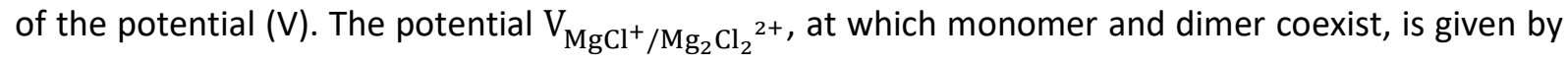

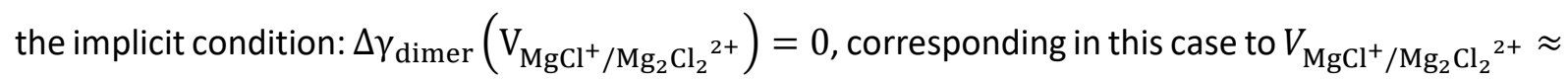
2.4 V/Mg). For potential lower than $2.4 \mathrm{~V} / \mathrm{Mg}, \Delta \gamma_{\text {dimer }}(\mathrm{V})<0$ indicating that the dimer is more stable than the monomer (Fig. 3).

With this first example, we observe that in contrast to the calculations for the bulk, a "nonelectrochemical equilibrium" at interface has a dependency on the potential, even without formal electron or chloride exchange. The reason is that the interface charge becomes more and more positive for oxidative potentials. The resulting electric field is increasingly destabilizing the doubly charged $\mathrm{Mg}_{2} \mathrm{Cl}_{2}(\mathrm{DME})_{4}^{2+}$ relatively to the singly charged $\mathrm{MgCl}(\mathrm{DME})_{3}^{+}$. Destabilization of $\mathrm{Mg}_{2} \mathrm{Cl}_{2}(\mathrm{DME})_{4}^{2+}$ reaches a point where $\mathrm{MgCl}(\mathrm{DME})_{3}^{+}$becomes more stable in the double layer. In the bulk of the electrolyte, macroscopic electric fields are screened, thus potential change does not impact the relative stability of $\mathrm{MgCl}(\mathrm{DME})_{3}^{+}$and $\mathrm{Mg}_{2} \mathrm{Cl}_{2}(\mathrm{DME})_{4}^{2+}$. This is discussed in detail in the next section.

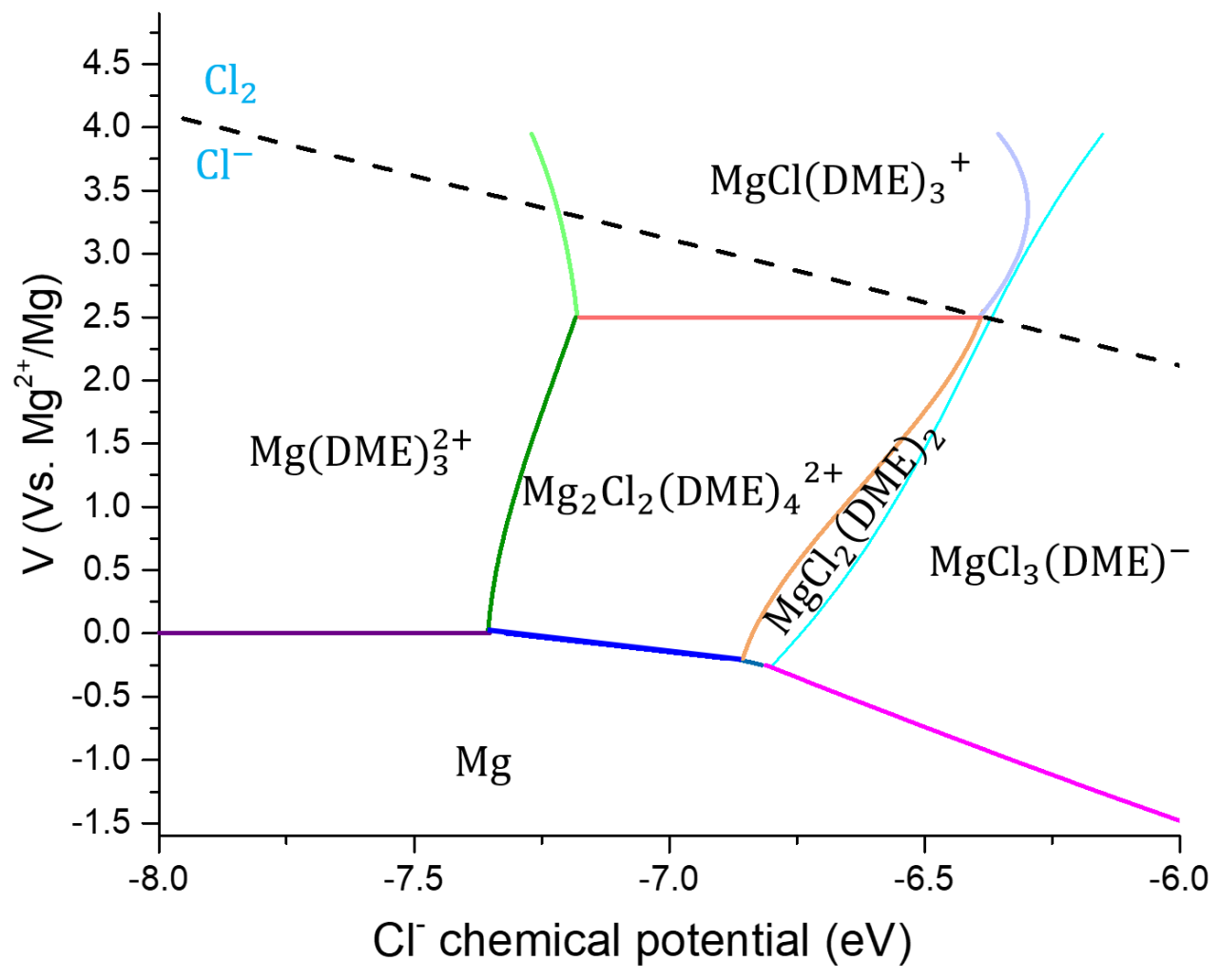


Figure 3: Interface Pourbaix diagram. The main difference in comparison to the bulk Pourbaix diagram is that non-electrochemical equilibrium at the interface is potential dependent although formally no electron or $\mathrm{Cl}^{-}$exchange occurs (sloped lines), whereas this was not the case for the bulk diagram (vertical lines). The potential scale is referred to $\mathrm{Mg}^{2+} / \mathrm{Mg}$ redox pair.

Another "non-electrochemical" equilibrium at the interface but with chloride exchange is given by:

$\operatorname{MgCl}(\mathrm{DME})_{3}^{+} / \mathbb{E}(V)+\mathrm{Cl}^{-} \rightleftarrows \mathrm{MgCl}_{2}(\mathrm{DME})_{2} / \mathbb{E}(V)+\mathrm{DME}$

As usual, a negative sign of the free electrochemical energy means that the products are more stable than the reactants and the equation corresponding to the equilibrium written as electrochemical free energy gives:

$\gamma_{\mathrm{Cl}^{-}}(\mathrm{V})=\mu_{\mathrm{Cl}^{-}}(\mathrm{V})+\mathrm{FV}=\gamma_{\mathrm{MgCl}(\mathrm{DME})_{3}^{+} / \mathbb{E}(\mathrm{V})}(\mathrm{V})-\gamma_{\mathrm{MgCl}_{2}(\mathrm{DME})_{2} / \mathbb{E}(\mathrm{V})}(\mathrm{V})+\mu_{\mathrm{DME}}$

$\mu_{\mathrm{Cl}^{-}}(\mathrm{V})=\gamma_{\mathrm{MgCl}(\mathrm{DME})_{3}^{+} / \mathbb{E}(\mathrm{V})}(\mathrm{V})-\gamma_{\mathrm{MgCl}_{2}(\mathrm{DME})_{2} / \mathbb{E}(\mathrm{V})}(\mathrm{V})+\mu_{\mathrm{DME}}-\mathrm{FV}$

The curve for the frontier between $\mathrm{MgCl}(\mathrm{DME})_{3}^{+}$and $\mathrm{MgCl}_{2}(\mathrm{DME})_{2}$ domains is directly given by this expression linking the chemical potential of chloride $\mu_{\mathrm{Cl}^{-}}$with the applied potential $V$ by means of potential-dependent surface free energies. The obtained frontier is not vertical as in a bulk Pourbaix diagram but is potential-dependent (Fig. 3). The slope of the frontier hints that this process becomes partially associated with some electron exchange at the interface due to surface polarization (vide infra).

\section{Electrochemical interface processes}

The simplest redox process is the purely electrochemical reaction, without $\mathrm{Cl}^{-}$exchange given by:

$\operatorname{Mg}(\mathrm{DME})_{3}^{2+} / \mathbb{E}(V) \rightleftarrows \mathrm{Mg}+3 \mathrm{DME}+\emptyset / \mathbb{E}(V)$

The associated frontier between $\mathrm{Mg}(\mathrm{DME})_{3}^{2+}$ and $\mathrm{Mg}$ is independent of the $\mathrm{Cl}^{-}$chemical potential and can be found by writing the reaction free energy $\Delta \gamma_{\mathrm{Mg}^{2+} / \mathrm{Mg}}$ :

$\Delta \gamma_{\mathrm{Mg}^{2+} / \mathrm{Mg}}(\mathrm{V})=\mu_{\mathrm{Mg}}+3 \mu_{\mathrm{DME}}+\gamma_{\varnothing / \mathbb{E}}(\mathrm{V})-\gamma_{\mathrm{Mg}(\mathrm{DME})_{3}^{2+} / \mathbb{E}}(\mathrm{V})$

The equilibrium potential $\mathrm{V}_{\mathrm{Mg}^{2+} / \mathrm{Mg}}$ separating the $\mathrm{Mg}^{2+}$ and $\mathrm{Mg}$ domain is obtained when the implicit condition $\Delta \gamma_{\mathrm{Mg}^{2+} / \mathrm{Mg}}\left(\mathrm{V}_{\mathrm{Mg}^{2+} / \mathrm{Mg}}\right)=0$ is reached. For the computed system, $\mathrm{V}_{\mathrm{Mg}^{2+} / \mathrm{Mg}} \approx 0 \mathrm{~V} / \mathrm{Mg}$, consistent with previous calculations and the bulk value. ${ }^{21}$ This process is independent of the $\mathrm{Cl}^{-}$ 
chemical potential, and thus corresponds to a horizontal line separating the $\mathrm{Mg}(\mathrm{DME})_{3}^{2+}$ from the $\mathrm{Mg}$ domain on the diagram (Fig. 3).

Other electrochemical processes imply the exchange of both electron and chloride. An example is given by:

$\mathrm{MgCl}_{2}(\mathrm{DME})_{2} / \mathbb{E} \rightleftarrows \mathrm{Mg}+2 \mathrm{DME}+\emptyset / \mathbb{E}+2 \mathrm{Cl}^{-}$

The corresponding surface electrochemical free energy equation is then:

$\gamma_{\mathrm{MgCl}_{2}(\mathrm{DME})_{2} / \mathbb{E}}(\mathrm{V})=\mu_{\mathrm{Mg}}+2 \mu_{\mathrm{DME}}+\gamma_{\varnothing / \mathbb{E}}(\mathrm{V})+2 \gamma_{\mathrm{Cl}^{-}}(\mathrm{V})$

This chemical equation gives the curve delimitating the $\mathrm{Mg}$ and $\mathrm{MgCl}_{2}(\mathrm{DME})_{2}$ and leads to:

$\mu_{\mathrm{Cl}^{-}}^{\text {eq.17 }}(\mathrm{V})=\frac{\gamma_{\mathrm{MgCl}_{2}(\mathrm{DME})_{2} / \mathbb{E}}(\mathrm{V})-\gamma_{\emptyset / \mathbb{E}}(\mathrm{V})-2 \mathrm{FV}-\mu_{\mathrm{Mg}}-2 \mu_{\mathrm{DME}}}{2}$

The corresponding curve is close to (but not exactly) a straight line with a slope close to - 1 as shown in Fig. 3.

All considered processes used to build the interface Pourbaix diagram can be extrapolated from these examples and are given in the Supporting Information $\mathbf{S 5}$ with the equations for the associated frontier lines. The existence condition for a domain is the same as a classical Pourbaix diagram (i.e. existence domains should not be separated). Therefore, all the possible equilibria were investigated and the total interface diagram was built and shown in Fig. 3.

\section{Results and Discussion}

Note that the Pourbaix diagrams are build based on thermodynamic stabilities of the species, with the kinetics of the system not being considered. Thus, the diagram tells us which $\mathrm{Mg}_{x} \mathrm{Cl}_{y} \mathrm{DME}_{z}^{(2 x-y)+}$ specie is the most abundant at equilibrium determined by a specific potential and chloride chemical potential/concentration, but this does not mean that other species cannot be present at that point, albeit in smaller concentrations.

\subsection{Bulk Pourbaix diagram}

The Pourbaix diagram for bulk electrolyte is shown in Fig 2. For low $\mu_{C l^{-}}$(low chloride concentration) the stable specie is $\operatorname{Mg}(\mathrm{DME})_{3}^{2+}$, in agreement with previous theoretical and experimental work. ${ }^{14,21,22}$ $\mathrm{Mg}(\mathrm{DME})_{3}^{2+}$ is computed to undergo reduction at a potential of $-2.4 \mathrm{~V} / \mathrm{SHE}\left(0 \mathrm{~V} \mathrm{vs} . \mathrm{Mg}^{\prime \prime} / \mathrm{Mg}^{0}\right)$ close to the experimental potential. ${ }^{21,22,50}$ Increasing chloride concentration leads to the formation of 
monomeric chloride complexes or multimeric Mg species, as observed experimentally. ${ }^{14,16-18,51}$ Our bulk diagram is consistent with the experimental observation showing that $\operatorname{Mg}(\mathrm{DME})_{3}^{2+}$, $\mathrm{Mg}_{2} \mathrm{Cl}_{2}(\mathrm{DME})_{4}^{2+}$ dimer, $\mathrm{Mg}_{3} \mathrm{Cl}_{4}(\mathrm{DME})_{5}{ }^{2+}, \mathrm{MgCl}_{2}(\mathrm{DME})_{2}$, can be formed with increasing chloride chemical potential (i.e. concentration). ${ }^{14} \mathrm{MgCl}(\mathrm{DME})_{3}^{+}$is not found under these conditions as it is always found less stable than the dimer $\mathrm{Mg}_{2} \mathrm{Cl}_{2}(\mathrm{DME})_{4}^{2+}$. Finally, with increasing $\mathrm{Cl}^{-}$concentration $\mathrm{MgCl}_{2}(\mathrm{DME})_{2}$ should convert into $\mathrm{MgCl}_{3}(\mathrm{DME})^{-}$. Note that $\mathrm{MgCl}_{3}(\mathrm{DME})^{-}$is not observed experimentally in the classical $\mathrm{Mg}(\mathrm{TFSI})_{2} / \mathrm{MgCl}_{2}$ mixture. This is presumably due to the low precipitation limit of $\mathrm{MgCl}_{2}$ that prevents reaching high $\mathrm{Cl}^{-}$chemical potential under experimental conditions. Nevertheless, $\mathrm{MgCl}_{3}(\mathrm{DME})^{-}$was observed in the electrolyte containing $\mathrm{MgCl}_{2} / \mathrm{AlCl}_{3}$ mixture. ${ }^{16}$ The maximum $\mathrm{Cl}^{-}$chemical potential that can be reached is probably larger than what can be obtained from $\mathrm{MgCl}_{2} / \mathrm{Mg}(\mathrm{TFSI})_{2}$ mixture. In this case, $\mathrm{AlCl}_{3}$ should behave like a Lewis acid but probably reacts with the electrolyte to generate " $\mathrm{AlCl}_{2}{ }^{+}$" and one $\mathrm{Cl}^{-}$behaving as a chlorination agent that allows achieving $\mathrm{MgCl}_{3}(\mathrm{DME})^{-}$. Therefore, the computed $\mathrm{MgCl}_{3}(\mathrm{DME})_{2}^{-}$could possibly be formed in the electrolyte bulk only if a chlorination agent is added to the electrolyte allowing to go beyond the $\mathrm{MgCl}_{2}$ chemical potential limit. Finally, the high oxidation limit of the diagram given by the $\mathrm{Cl}_{2} / \mathrm{Cl}^{-}$redox pair agrees with the standard potential (1.36 V/SHE). This line gives the upper limit of stability for different chlorinated magnesium complexes that should decompose to form $\mathrm{Cl}_{2}$ above this limit. This is particularly important while envisioning high potential Mg-battery as this will partly control the electrolyte stability for the cathode material. The different species occurring in the bulk of the electrolyte are numerous, but fully correspond to what is observed experimentally ${ }^{14}$ validating the bulk electrolyte approach.

\subsection{Interface Pourbaix diagram}

The Pourbaix diagram at the interface (Fig. 3) can be similar or different from the one in the bulk (a superposition graph is given in Fig. S5). First, for $\mu_{\mathrm{Cl}^{-}}<-7.75 \mathrm{eV}$, all the $\mathrm{Mg}^{\prime \prime} / \mathrm{Mg}^{0}$ frontiers are similar for the interface and the $\left(0.4 \mathrm{~mol}^{\mathrm{L}} \mathrm{L}^{-1}\right)$ bulk showing that " $\mathrm{Mg}$ "1" chemical potential in Mg-complexes are similar even if their formal concentration is different by $20 \%$. This is a direct consequence of the local electric fields at the interface that is modulating the chemical potential of the $\mathrm{Mg}_{x} \mathrm{Cl}_{y} \mathrm{DME}_{z}(2 x-y)+$ complexes and thus the specie type and concentration. The different behavior for high $\mathrm{Cl}^{-}$chemical potential of the interfacial $\mathrm{MgCl}_{3}(\mathrm{DME})_{2}^{-}$suggests that its amount at the interface should decrease to maintain equilibrium with the bulk species. Then, if these frontiers can be similar, the stable species at the interface are not all the same as in the bulk at a given chloride chemical potential. The trimeric $\mathrm{Mg}_{3} \mathrm{Cl}_{4}(\mathrm{DME})_{5}{ }^{2+}$ species is not found stable at the interface and the monomeric $\operatorname{MgCl}(\mathrm{DME})_{3}^{+}$is found to replace the dimer at oxidative potentials higher than $2.4 \mathrm{~V} / \mathrm{Mg}$. Second, all the frontiers are 
distorted and shifted. Vertical lines in the bulk separating two different chloride complexes become tilted at the interface. This induces a large change in the different frontiers at the interface relative to bulk, in particular with the domain of $\mathrm{MgCl}_{3}(\mathrm{DME})_{2}^{-}$that is increased towards the lower chemical potential. This is a direct consequence of an interaction between the solvated Mg species and the electrode that changes the stability of the different complexes.

To better understand the cause of these changes, we first consider a general chlorination reaction given by:

$X^{+} / \mathbb{E}(V)+C l^{-} \rightleftarrows \mathrm{XCl} / \mathbb{E}(V)$

$\mu_{C l^{-}}(V)=\gamma_{\mathrm{XCl} / \mathbb{E}}(V)-\gamma_{X^{+} / \mathbb{E}}(V)-F V=\mu_{X C l}^{0}-\mu_{X^{+}}^{0}-F V_{m}^{0}+\epsilon F\left(V-V_{m}^{0}\right)$

with $\mu_{X C l}^{0}$ and $\mu_{X^{+}}^{0}$ the energies of the uncharged interfaces, $V_{m}^{0}=\left(V_{X^{+}}^{0}-V_{X C l}^{0}\right) / 2, V_{X C l}^{0}$ and $V_{X^{+}}^{0}$ the potentials of zero-charge for the uncharged $\mathrm{XCl} / \mathbb{E}$ and $\mathrm{X}^{+} / \mathbb{E}$ interfaces, and $\epsilon=\frac{C}{F}\left(V_{X^{+}}^{0}-V_{X C l}^{0}\right)-$ $1=\Delta n_{0}-1 .^{22}$ The full derivation is given in the SI $\mathbf{S 6}$.

The slope of the curve $\epsilon$ is directly linked with the difference of charge between the considered surface and the number of exchanged chloride ions. This number can be positive or negative and corresponds to the slope inclination. When the slope is positive (negative) the number of exchanged electrons with the electrode is slightly larger (lower) than 0 . As an example, at $2.9 \mathrm{~V} / \mathrm{Mg}$, the equilibrium frontier between $\operatorname{Mg}(\mathrm{DME})_{3}^{2+}$ and $\operatorname{MgCl}(\mathrm{DME})_{3}^{+}$is given by the equation:

$\operatorname{Mg}(\mathrm{DME})_{3}^{2+} / \mathbb{E}(\mathrm{V})+\mathrm{Cl}^{-}-0.05 \mathrm{e}^{-} \rightleftarrows \operatorname{MgCl}(\mathrm{DME})_{3}^{+} / \mathbb{E}(\mathrm{V})$

while at $1.4 \mathrm{~V} / \mathrm{Mg}$, the frontier between $\mathrm{Mg}(\mathrm{DME})_{3}^{2+}$ and $\mathrm{Mg}_{2} \mathrm{Cl}_{2}(\mathrm{DME})_{4}^{2+}$ is given by the equation:

$$
\mathrm{Mg}(\mathrm{DME})_{3}^{2+} / \mathbb{E}(\mathrm{V})+\mathrm{Cl}^{-}+0.04 \mathrm{e}^{-} \rightleftarrows \frac{1}{2} \mathrm{Mg}_{2} \mathrm{Cl}_{2}(\mathrm{DME})_{4}^{2+} / \mathbb{E}(\mathrm{V})+\mathrm{DME}
$$

In both cases, a small fraction of electron must be added or removed from the electron reservoir (i.e. the generator), to keep the surface potential constant with the undergoing reaction.

Similar effects can be found for the lines corresponding to electrochemical reactions such as:

$\mathrm{Mg}(\mathrm{DME})_{3}^{2+} / \mathbb{E}(\mathrm{V})+2.2 \mathrm{e}^{-} \rightleftarrows \mathrm{Mg}^{0}+\emptyset / \mathbb{E}(\mathrm{V})+3 \mathrm{DME}$

where the amount of exchange charges is slightly different from the two electrons needed for $\mathrm{Mg}^{2+}$ reduction. 
As shown in our previous work, these differences are linked with the different electrochemical response of $X^{+} / \mathbb{E}$ and $\mathrm{XCl} / \mathbb{E}$ interfaces due to the different solvate/surface interactions. ${ }^{22}$ This noninteger behavior is specific of elementary reaction steps/equilibrium at the interfaces, but will cancel out over the whole redox process that is associated with an exchange of an integer number of electron (see ref [22] for details).

\subsection{Concentration effects in bulk electrolyte and at the interface}

Thus, Interfacial stability of $\mathrm{Mg}_{\mathrm{x}} \mathrm{Cl}_{\mathrm{y}}(\mathrm{DME})_{\mathrm{z}}^{(2 \mathrm{x}-\mathrm{y})+}$ complexes within the double layer is significantly different from the ones in the bulk of the electrolyte, but their equilibrium properties are obviously linked. Indeed, the global system can be decomposed into three domains: the bulk of electrolyte, the double layer/interface and the Mg-electrode. There is a direct chemical equilibrium between the bulk of electrolyte and the double layer, and another one between the double layer and the Mg-electrode. Nevertheless, because of these chemical equilibria, intensive parameters (e.g. electrode electrochemical potential) are controlled by the bulks species concentrations/chemical potentials (i.e. electrolyte $\mathrm{Mg}$-species and $\mathrm{Mg}$-electrode) which are orders of magnitude more abundant than the interface ones: the interface species are just intermediates and thus do not impact the global equilibrium and energetics associated with the bulk species. Then, under equilibrium conditions, measured thermodynamic properties will be dominated by bulks (that impose all chemical potentials) as given by the Nernst relation and blind to the specific chemistry occurring at the interface. But, even in the same conditions (chloride chemical potential, electrode potential, T, P...), Mg-species in the electrolyte bulk and in the double layer can be different, because the interaction with the metal surface is strongly modifying the different molecules energetics in the double layer. For example, at a chloride chemical potential of $-7 \mathrm{eV}$ under equilibrium with the $\mathrm{Mg}$ electrode, the specie stable in the bulk is $\mathrm{Mg}_{3} \mathrm{Cl}_{4}(\mathrm{DME})_{5}{ }^{2+}$ while $\mathrm{Mg}_{2} \mathrm{Cl}_{2}(\mathrm{DME})_{4}^{2+}$ is stable in the double layer. The fine tuning of the equilibrium in the double layer is also controlled by concentration effects. Similarly, because of the electrode interactions, concentrations in the electrolyte bulk and at the interface are different even if the stable species are identical. But, the "Mg" chemical potential in all the Mg-complexes in the electrolyte bulk and at the interface should be the same. The " $\mathrm{Mg}$ "” chemical potential is directly given by the $\mathrm{Mg}^{\prime \prime} / \mathrm{Mg}^{0}$ frontiers in the Pourbaix diagrams. Thus, the comparison of the interface (at a concentration of 0.33 mol. $\mathrm{L}^{-1}$ and coverage of $1 / 25$ ) and bulk (at a concentration of $0.4 \mathrm{~mol} . \mathrm{L}^{-1}$ ) Pourbaix diagrams (see Fig. S5), shows that the $\mathrm{Mg}^{\prime \prime} / \mathrm{Mg}^{0}$ frontiers are similar for experimentally relevant chloride chemical potentials (i.e. below $\mathrm{MgCl}_{2}$ bulk formation). The interface and the 0.4 mol. $\mathrm{L}^{-1}$ electrolyte bulk can be considered under equilibrium. The interface energetics is then following as thermodynamically imposed the electrolyte bulks energetics: this is validating the constant concentration approximation used for building the surface diagram. 
Thus, the present approach allows obtaining the average concentration change of Mg-complexes between the bulk and the double layer. This method could be extended to account for exact $\mathrm{Mg}$ concentration fluctuation with chloride and electron potential, in the double layer by adding a third grand canonical reservoir for $\mathrm{Mg}$ in the double layer (in complement of the electron and chloride ones). Nevertheless, in the present case, the constant " $\mathrm{Mg}$ " concentration approximation at the interface is precise enough to compare bulk and interface species. The knowledge of the exact species stable at the interface is of great importance as it is strongly impacting the reaction pathways of all surface electrochemical processes. ${ }^{52}$

\subsection{Beneficial effect of $\mathrm{Cl}^{-}$anion}

Among all interface processes, the electrochemical degradation of solvent is of great importance for Mg-batteries. As shown in our previous work, in the absence of chlorides, one DME molecule in the first solvation shell of $\mathrm{Mg}(\mathrm{DME})_{3}^{2+}$ starts gaining electrons and becomes electrochemically activated at a potential as low as $-100 \mathrm{mV} / \mathrm{Mg}$. For a potential lower than $-800 \mathrm{mV} / \mathrm{Mg}$, the DME molecule even becomes unstable and spontaneously decomposes. ${ }^{21}$ This leads to formation of a very stable species $\mathrm{Mg}(\mathrm{DME})_{2}\left(\mathrm{OCH}_{3}\right)_{2}$ in which $\mathrm{Mg}$ is trapped and can no longer be deposited for a reasonable overpotential. It has been observed experimentally that the inclusion of $\mathrm{MgCl}_{2}$ into the $\mathrm{MgTFSI}_{2} / \mathrm{DME}$ electrolyte has beneficial effects on the applied current density, coulombic efficiency, and reversible deposition and dissolution. ${ }^{12-18} \mathrm{~A}$ way of understanding the effect of chloride adjunction is by looking at the thermodynamic and kinetic stability of the different $\mathrm{Mg}_{\mathrm{x}} \mathrm{Cl}_{\mathrm{y}} \mathrm{DME}_{\mathrm{z}}{ }^{(2-y)+}$ species occurring at the interface at different $\mathrm{Cl}^{-}$chemical potentials.

First, thermodynamic $\mathrm{Mg}^{\mathrm{II}} / \mathrm{Mg}^{0}$ redox potential is influenced by chloride chemical potential increase as it decreases from $0 \mathrm{~V} / \mathrm{Mg}$ for free $\mathrm{Mg}(\mathrm{DME})_{3}^{2+}$ to between $0 \mathrm{~V} / \mathrm{Mg}$ and $-0.2 \mathrm{~V} / \mathrm{Mg}$ for $\mathrm{Mg}_{2} \mathrm{Cl}_{2}(\mathrm{DME})_{4}^{2+},-0.2 \mathrm{~V} / \mathrm{Mg}$ and $-0.3 \mathrm{~V} / \mathrm{Mg} \mathrm{V} / \mathrm{Mg}$ for $\mathrm{MgCl}_{2}(\mathrm{DME})_{2}$, and below $-0.3 \mathrm{~V} / \mathrm{Mg}$ for $\mathrm{MgCl}_{3}(\mathrm{DME})_{2}^{-}$. This decrease remains small in contrast to $\mathrm{CH}_{3} \mathrm{O}^{-}$ligands and thus chloride ligands do not deactivate the $\mathrm{Mg}^{\prime \prime}$ reduction.

The protecting effect of chloride is also seen in the stabilization of DME molecules in $\mathrm{Mg}_{\mathrm{x}} \mathrm{Cl}_{\mathrm{y}} \mathrm{DME}_{\mathrm{z}}{ }^{(2-y)+}$ complexes: while $\mathrm{Mg}(\mathrm{DME})_{3}^{2+}$ becomes unstable and undergoes spontaneous decomposition beyond $-800 \mathrm{mV} / \mathrm{Mg}$, all chlorinated complexes remain at least metastable up to our computational limit of $-1.6 \mathrm{~V} / \mathrm{Mg}$, suggesting enhanced stability. To investigate this effect more precisely, we define a kinetic activation parameter using electron transfer criteria, by determining the potential at which the Mg complex starts gaining electrons from the Mg surface. This is done by looking 
at the net charge computed on the surface as described in detail in our previous work. ${ }^{21}$ The kinetic stability limit is $-100 \mathrm{mV} / \mathrm{Mg}$ for non-chlorinated $\mathrm{Mg}(\mathrm{DME})_{3}^{2+}$, and decreases down to $-300 \mathrm{mV} / \mathrm{Mg}$ for $\mathrm{Mg}_{2} \mathrm{Cl}_{2}(\mathrm{DME})_{4}^{2+}$, while electron transfer is neither observed for $\mathrm{MgCl}_{2}(\mathrm{DME})_{2}$ nor for $\mathrm{MgCl}_{3}$ (DME) ${ }^{-}$down to $-1.6 \mathrm{~V} / \mathrm{Mg}$ that was the lower limit of our study (Fig. 4). This effect is underlined by the Fukui function. ${ }^{53}$ The Fukui function gives some insights into the redox center as seen in Fig. 5. If the Fukui function on a molecule is dominantly positive, the molecule is a redox center; if the Fukui function is half positive half negative, it suggests that the molecule is not the redox center but undergoes electronic polarization due to a strong local electric field. The Fukui function of $\mathrm{Mg}_{2} \mathrm{Cl}_{2}$ (DME) ${ }_{4}^{2+}$ presents as many positive and negative contributions, suggesting that the complex only undergoes polarization due to the charged $\mathrm{Mg}$ surface. The Fukui function of $\operatorname{Mg}(\mathrm{DME})_{3}^{2+}$ shows dominant positive contribution of the DME molecule on top of the $\mathrm{Mg}$ atom: electrons are transferred to this molecule that is partially reduced and electrochemically activated. Thus, one of the DME molecule $\operatorname{Mg}(\mathrm{DME})_{3}^{2+}$ starts to be reduced at $-0.3 \mathrm{~V} / \mathrm{Mg}$ while at the same potential no $\mathrm{DME}$ of $\mathrm{Mg}_{2} \mathrm{Cl}_{2}(\mathrm{DME})_{4}^{2+}$ is reduced. $\mathrm{Cl}^{-}$anion acts similarly to the $\mathrm{OCH}_{3}{ }^{-}$anions in the $\mathrm{Mg}(\mathrm{DME})_{2}\left(\mathrm{OCH}_{3}\right)_{2}$ structure formed after DME decomposition. ${ }^{21}$ Both anions prevent further DME decomposition in the first solvation shell by decreasing the electrophilic power of $\mathrm{Mg}^{2+}$ by electron donation. ${ }^{14,16}$

The operating domain defined as the potential range where $\mathrm{Mg}^{\|}$is still thermodynamically reduced while the attached DME molecules are not electrochemically activated are given in Fig. 4. The more chloride is added the more the operating domain increases. The maximum operating overpotential at the interface is only of $100 \mathrm{mV}$ for $\mathrm{Mg}(\mathrm{DME})_{3}^{2+}$ and increases to $250 \mathrm{mV}$ for $\mathrm{Mg}_{2} \mathrm{Cl}_{2}(\mathrm{DME})_{4}^{2+}$ and beyond $1.3 \mathrm{~V}$ for $\mathrm{MgCl}_{2}(\mathrm{DME})_{2}$ and $\mathrm{MgCl}_{3}(\mathrm{DME})^{-}$. By mixing $\mathrm{MgCl}_{2} / \mathrm{Mg}(\mathrm{TFSI})_{2}$ salts in the electrolyte, chloride soluble species are formed in the bulk such as $\mathrm{Mg}_{3} \mathrm{Cl}_{4}(\mathrm{DME})_{5}{ }^{2+}$ that can convert into soluble $\mathrm{MgCl}_{2}(\mathrm{DME})_{2}$ at the interface preventing DME degradation and still allowing $\mathrm{Mg}^{\prime \prime}$ reduction. Thus, combining bulk and interfacial Pourbaix diagram allows getting insights in the reactivity as a function of a ligand chemical potential of an electrochemical system, and provides better understanding of the consequences of the changes in the active species on the electrode reactivity. 


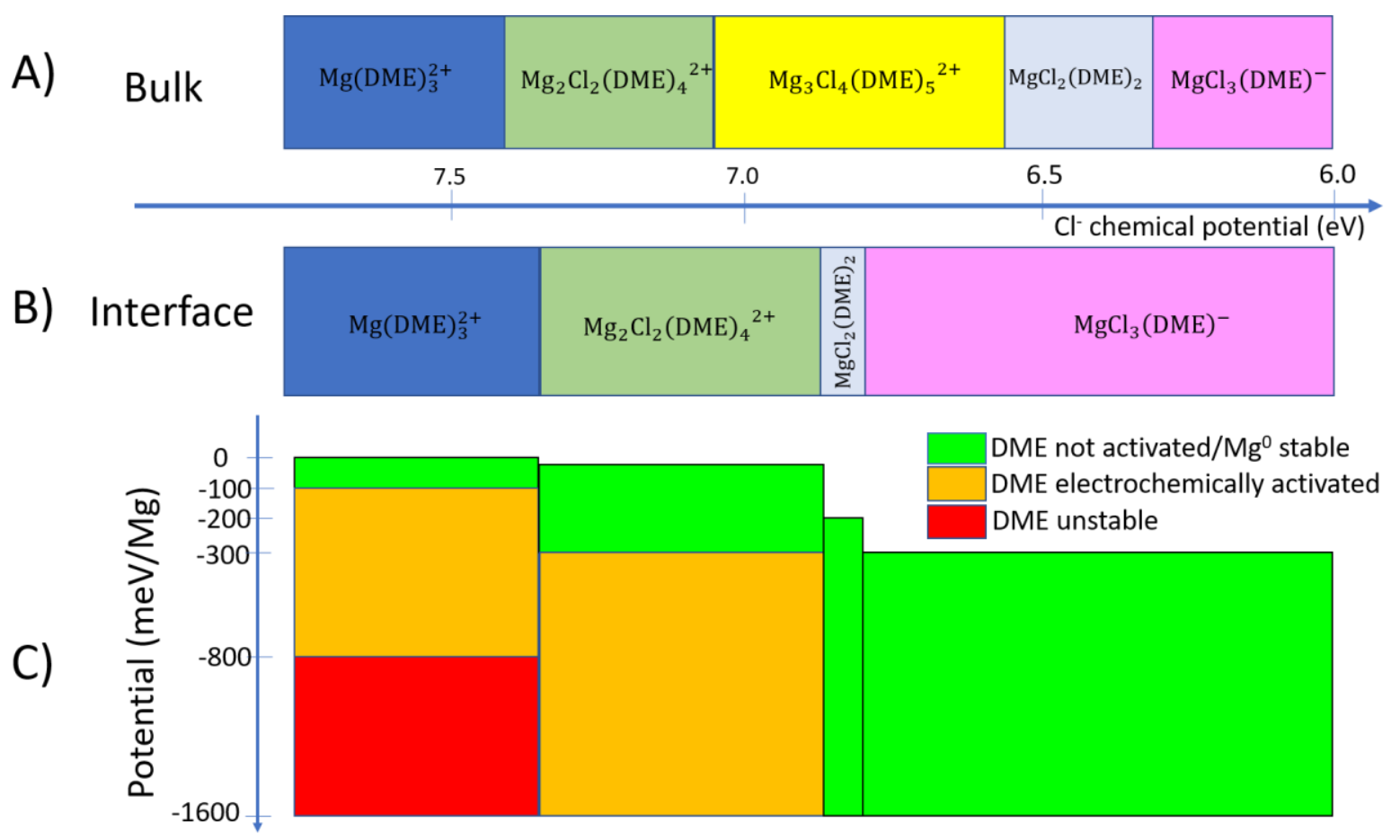

Figure 4. Stable species at the $M g^{\prime \prime} / \mathrm{Mg}^{0}$ frontier as a function of the chloride chemical potential in (A) bulk, and at (B) interface. The Mg-coordinated DME stability is given in (C) as a function of the surface species and the applied potential (vs. Mg). The colored domains correspond to the maximum thermodynamic potential range where interfacial $\mathrm{Mg}^{\prime \prime}$ is reduced into $\mathrm{Mg}^{\circ}$, i) with no activation of the coordinated DME molecule (green), ii) with partial electron transfer to the Mg-coordinated DME inducing partial activation and increasing the kinetic of DME fragmentation (orange), iii) with unstable solvate and spontaneous electrochemical induced DME fragmentation (red). Note that the green zones correspond to the working overpotential where $\mathrm{Mg}^{\prime \prime}$ is reduced into $\mathrm{Mg}^{\circ}$ but where the solvent in the solvation shell of Mg remains kinetically stable. 


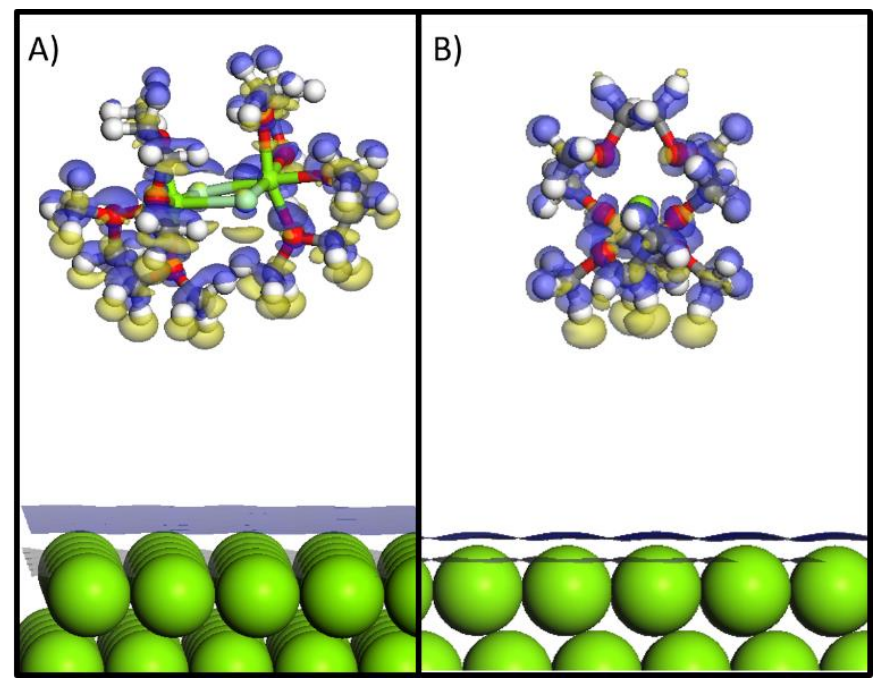

Figure 5: Isodensity of the Fukui functions for (A) $\mathrm{Mg}_{2} C l_{2}(D M E)_{4}^{2+}$ and (B) $M g(D M E)_{3}^{2+}$ at a potential of $-0.3 \mathrm{~V} / \mathrm{Mg}$. The positive contribution (increased electron density) is in blue, while the negative one (decreased electron density) is in yellow.

\section{Conclusion}

Based on our electrochemical DFT approach that allows simulations of the potential dependent processes on interfaces, we present herein a methodology for building a Pourbaix potential vs. ligand chemical potential diagram from ab initio calculations. The diagram was not only built for the bulkstability of studied $\mathrm{Mg}_{x} \mathrm{Cl}_{y} \mathrm{DME}_{z}^{(2 x-y)+}$ species, but was also extended to the stability at the interface ones. The bulk Pourbaix diagram obtained via DFT is in excellent agreement with experimental data, validating the approach. The interface Pourbaix diagram presents strong differences with the bulk one. Firstly, interaction of the solvated $\mathrm{Mg}$ species with the $\mathrm{Mg}$ anode results in sloped frontiers between different species in the interface diagram. In contrast, the frontiers in the bulk diagram are potential independent and thus vertical. Secondly, these frontiers are also slightly shifted, again due to the potential dependence of the stability of species at the interface. Thirdly, the stable specie at the interface can be different from the on in the bulk.

We have focused on various $\mathrm{Mg}_{x} \mathrm{Cl}_{y} \mathrm{DME}_{z}^{(2 x-y)+}$ species that were also experimentally observed in $\mathrm{MgTFSI}_{2} / \mathrm{MgCl}_{2} / \mathrm{DME}$ electrolyte solutions. It has been shown that these solutions allow the $\mathrm{Mg}$ battery to have better electrochemical performance, i.e. higher current density, better columbic efficiency, and lower overpotential for stripping and platting, than electrolytes containing only $\mathrm{MgTFSI}_{2}$ salt solvated in DME. These Pourbaix diagrams allow identifying the $\mathrm{Mg}_{x} \mathrm{Cl}_{y} \mathrm{DME}_{z}^{(2 x-y)+}$ complexes in the bulk and at the interface. Using an electrochemical activation criteria at the interface, $\mathrm{Mg}_{x} \mathrm{Cl}_{y} \mathrm{DME}_{z}{ }^{(2 x-}$ y)+ with the higher chloride content were shown not to undergo DME fragmentation. Finally, all the 
above observations of differences between bulk and interface highlight the importance of including potential dependent effects at the interface. This makes calculations a suitable tool for identifying stable species at the interface where the majority of the reactions critical for the battery operation are occurring. Thus, calculations allow investigation of the electrochemical processes happening at the electrode-electrolyte interface. Indeed, using the theoretical insights, we were able to investigate some of the mechanisms behind the beneficial effect of $\mathrm{Cl}^{-}$anion on $\mathrm{Mg}$ battery operation.

The methodology is transferable to other electrolytes, for instance in $\mathrm{Al}$ batteries, where $\mathrm{AlCl}_{3}$ is typically used but also to nearly any electrochemical system combining bulk electrolyte and electrolyte/electrode interface. We thus believe it will serve as a valuable tool for the wider electrochemical community, from energy storage and conversion to corrosion prevention.

\section{Supporting Information}

Supporting information gives detailed example on the procedure used to extract the free electrochemical energies and how they are used to draw Frontiers in the Pourbaix diagram; the full set of equations used to compute the Pourbaix diagram for the bulk of the electrolyte and at the interface, the procedure used to compute the electrostatic energy dependency with ion concentration; comparison between Pourbaix diagrams at different concentration and for bulk and interface diagrams; the derivation of the frontier equation at the interface as a function of interface parameters; the computed energies and free electrochemical energy curves (section S7).

\section{Acknowledgements}

Financial support from the French National Research Agency through the Labex STORE-EX project (ANR-10LABX-76-01) is gratefully acknowledged and appreciated. Financial support from the Slovenian Research Agency (research project Z2-1864 and research core funding P2-0393) and Honda R\&D Europe (Germany) is gratefully acknowledged and appreciated. This work was performed using HPC resources from GENCI-CINES (Grant 2019-A0060910369). All authors thank Campus France and MarieLiesse Doublet for fruitful discussions.

\section{References}

(1) Persson, K. A.; Waldwick, B.; Lazic, P.; Ceder, G. Prediction of Solid-Aqueous Equilibria : Scheme to Combine First-Principles Calculations of Solids with Experimental Aqueous States. Phys. Rev. B 2012, 85, 235438. https://doi.org/10.1103/PhysRevB.85.235438. 
(2) Mamatkulov, M.; Filhol, J. S. An Ab Initio Study of Electrochemical vs. Electromechanical Properties: The Case of CO Adsorbed on a Pt(111) Surface. Phys. Chem. Chem. Phys. 2011, 13 (17), 7675-7684. https://doi.org/10.1039/c0cp01444c.

(3) Bard, A. J.; Faulkner, L. R. Electrochemical Methods 2nd Edition; John Wiley \& Sons; New York; 2001.

(4) Mohtadi, R.; Mizuno, F. Magnesium Batteries: Current State of the Art, Issues and Future Perspectives. Beilstein J. Nanotechnol. 2014, 5, 1291-1311. https://doi.org/10.3762/bjnano.5.143.

(5) Linden, D.; Reddy, T. B. Handbook of Batteries; 2002. https://doi.org/10.1002/9780470933886.ch1.

(6) Yoo, H. D.; Shterenberg, I.; Gofer, Y.; Gershinsky, G.; Pour, N.; Aurbach, D. Mg Rechargeable Batteries: An on-Going Challenge. Energy Environ. Sci. 2013, 6 (8), 2265-2279. https://doi.org/10.1039/c3ee40871j.

(7) Zhao-karger, Z.; Elisa, M.; Bardaji, G.; Fuhr, O.; Fichtner, M. A New Class of Non-Corrosive, Highly Efficient Electrolytes for Rechargeable Magnesium Batteries. J. Mater. Chem. A Mater. energy Sustain. 2017, 5 (22), 10815-10820. https://doi.org/10.1039/c7ta02237a.

(8) Wang, H.; Feng, X.; Chen, Y.; Liu, Y.; Han, K. S.; Zhou, M.; Engelhard, M. H.; Murugesan, V.; Assary, R. S.; Liu, T. L.; Henderson, W. Reversible Electrochemical Interface of $\mathrm{Mg}$ Metal and Conventional Electrolyte Enabled by Intermediate Adsorption. ACS Energy Lett. 2020, 5, 200-206. https://doi.org/10.1021/acsenergylett.9b02211.

(9) Matsui, M. Study on Electrochemically Deposited Mg Metal. J. Power Sources 2011, 196, 70487055. https://doi.org/10.1016/j.jpowsour.2010.11.141.

(10) Ling, C.; Banerjee, D.; Matsui, M. Study of the Electrochemical Deposition of Mg in the Atomic Level: Why It Prefers the Non-Dendritic Morphology. Electrochim. Acta 2012, 76, 270-274. https://doi.org/10.1016/j.electacta.2012.05.001.

(11) Attias, R.; Salama, M.; Hirsch, B.; Goffer, Y.; Aurbach, D. Anode-Electrolyte Interfaces in Secondary Magnesium Batteries. Joule 2019, 3 (1), 27-52. https://doi.org/10.1016/j.joule.2018.10.028.

(12) Shterenberg, I.; Salama, M.; Yoo, H. D.; Gofer, Y.; Park, J.-B.; Sun, Y.-K.; Aurbach, D. Evaluation of $\left(\mathrm{CF}_{3} \mathrm{SO}_{2}\right)_{2} \mathrm{~N}^{-}$(TFSI) Based Electrolyte Solutions for Mg Batteries. J. Electrochem. Soc. 2015, 162 (13), 7118-7128. https://doi.org/10.1149/2.0161513jes.

(13) Salama, M.; Shterenberg, I.; Gizbar, H.; Eliaz, N. N.; Kosa, M.; Keinan-Adamsky, K.; Afri, M.; Shimon, L. J. W.; Gottlieb, H. E.; Major, D. T.; Gofer, Y. Unique Behavior of Dimethoxyethane (DME)/Mg(N(SO2CF3)2)2Solutions. J. Phys. Chem. C 2016, 120 (35), 19586-19594. https://doi.org/10.1021/acs.jpcc.6b07733.

(14) Salama, M.; Shterenberg, I.; Shimon, L. J. W.; Keinan-Adamsky, K.; Afri, M.; Gofer, Y.; Aurbach, D. Structural Analysis of Magnesium Chloride Complexes in Dimethoxyethane Solutions in the Context 
of Mg Batteries Research. J. Phys. Chem. C 2017, 121 (45), 24909-24918. https://doi.org/10.1021/acs.jpcc.7b05452.

(15) Bitenc, J.; Firm, M.; Randon Vitanova, A.; Dominko, R. Effect of $\mathrm{Cl}^{-}$and TFSI- Anions on Dual Electrolyte Systems in a Hybrid $\mathrm{Mg} / \mathrm{Li}_{4} \mathrm{Ti}_{5} \mathrm{O}_{12}$ Battery. Electrochem. commun. 2017, 76, 29-33. https://doi.org/10.1016/j.elecom.2017.01.013.

(16) Barile, C. J.; Nuzzo, R. G.; Gewirth, A. A. Exploring Salt and Solvent Effects in Chloride-Based Electrolytes for Magnesium Electrodeposition and Dissolution. J. Phys. Chem. C 2015, 119, 1352413534. https://doi.org/10.1021/acs.jpcc.5b03508.

(17) Sa, N.; Pan, B.; Saha-shah, A.; Hubaud, A. A.; Vaughey, J. T.; Baker, L. A.; Liao, C.; Burrell, A. K. Role of Chloride for a Simple, Non-Grignard Mg Electrolyte in Ether- Based Solvents. ACS Appl. Mater. Interfaces 2016, 8, 16002-16008. https://doi.org/10.1021/acsami.6b03193.

(18) Pan, B.; Huang, J.; Sa, N.; Brombosz, S. M.; Vaughey, J. T.; Zhang, L.; Burrell, A. K.; Zhang, Z.; Liao, $\mathrm{C}$. $\mathrm{MgCl} 2$ : The Key Ingredient to Improve Chloride Containing Electrolytes for Rechargeable Magnesium-Ion Batteries. J. Electrochem. Soc. 2016, 163 (8), 1672-1677. https://doi.org/10.1149/2.0821608jes.

(19) See, K. A.; Chapman, K. W.; Zhu, L.; Wiaderek, K. M.; Borkiewicz, O. J.; Barile, C. J.; Chupas, P. J.; Gewirth, A. A. The Interplay of Al and Mg Speciation in Advanced Mg Battery Electrolyte Solutions. J. Am. Chem. Soc. 2016, 138, 328-337. https://doi.org/10.1021/jacs.5b10987.

(20) Canepa, P.; Jayaraman, S.; Cheng, L.; Curtiss, L. A.; Persson, A.; Ceder, G. Elucidating the Structure of the Magnesium Aluminum Chloride Complex Electrolyte For. Energy Environ. Sci. 2015, 8, 3718-3730. https://doi.org/10.1039/c5ee02340h.

(21) Kopač Lautar, A.; Bitenc, J.; Rejec, T.; Dominko, R.; Filhol, J.-S.; Doublet, M.-L. Electrolyte Reactivity in the Double Layer in Mg Batteries : An Interface Potential-Dependent DFT Study. J. Am. Chem. Soc. 2020, 142, 5146-5153. https://doi.org/10.1021/jacs.9b12474.

(22) Kopač Lautar, A.; Hagopian, A.; Filhol, J.-S. Modeling Interfacial Electrochemistry : Concepts and Tools. Phys. Chem. Chem. Phys. 2020, 22, 10569-10580. https://doi.org/https://doi.org/10.1039/C9CP06684E.

(23) Filhol, J.-S.; Neurock, M. Elucidation of the Electrochemical Activation of Water over Pd by First Principles. Angew. Chemie Int. Ed. 2006, 45 (3), 402-406. https://doi.org/10.1002/anie.200502540.

(24) Lespes, N.; Filhol, J.-S. Using the Electrochemical Dimension to Build Water/Ru(0001) Phase Diagram. Surf. Sci. 2015, 631, 8-16. https://doi.org/10.1016/J.SUSC.2014.06.017.

(25) Lespes, N.; Filhol, J. S. Using Implicit Solvent in Ab Initio Electrochemical Modeling: Investigating $\mathrm{Li}^{+} / \mathrm{Li}$ Electrochemistry at a Li/Solvent Interface. J. Chem. Theory Comput. 2015, 11 (7), 3375-3382. https://doi.org/10.1021/acs.jctc.5b00170.

(26) Taylor, C. D.; Wasileski, S. A.; Filhol, J. S.; Neurock, M. First Principles Reaction Modeling of the Electrochemical Interface: Consideration and Calculation of a Tunable Surface Potential from Atomic 
and Electronic Structure. Phys. Rev. B 2006, 73, 165402. https://doi.org/10.1103/PhysRevB.73.165402.

(27) Kresse, G.; Furthmüller, J. Efficiency of Ab-Initio Total Energy Calculations for Metals and Semiconductors Using a Plane-Wave Basis Set. Comput. Mater. Sci. 1996, 6 (1), 15-50. https://doi.org/10.1016/0927-0256(96)00008-0.

(28) Kresse, G.; Furthmüller, J. Efficient Iterative Schemes for Ab Initio Total-Energy Calculations Using a Plane-Wave Basis Set. Phys. Rev. B 1996, 54 (16), 11169-11186. https://doi.org/10.1103/PhysRevB.54.11169.

(29) Perdew, J. P.; Burke, K.; Ernzerhof, M. Generalized Gradient Approximation Made Simple. Phys. Rev. Lett. 1996, 77 (18), 3865-3868. https://doi.org/10.1103/PhysRevLett.77.3865.

(30) Kresse, G.; Joubert, D. From Ultrasoft Pseudopotentials to the Projector Augmented-Wave Method. Phys. Rev. B 1999, 59 (3), 1758-1775. https://doi.org/10.1103/PhysRevB.59.1758.

(31) Fishman, M.; Zhuang, H. L.; Mathew, K.; Dirschka, W.; Hennig, R. G. Accuracy of ExchangeCorrelation Functionals and Effect of Solvation on the Surface Energy of Copper. Phys. Rev. B 2013, 87 (24), 245402. https://doi.org/10.1103/PhysRevB.87.245402.

(32) Mathew, K.; Sundararaman, R.; Letchowrth-Weaver, K.; Arias, T. A.; Henning, R. G. Implicit Solvation Model for Density-Functional Study of Nanocrystal Surfaces and Reaction Pathways. J. Chem. Phys. 2014, 8, 084106. https://doi.org/10.1063/1.4865107.

(33) Steinmann, S. N.; Michel, C.; Schwiedernoch, R.; Filhol, J.; Sautet, P. Modeling the HCOOH / CO 2 Electrocatalytic Reaction: When Details Are Key. ChemPhysChem 2015, 16, 2307-2311. https://doi.org/10.1002/cphc.201500187.

(34) Hagopian, A.; Doublet, M.-L.; Filhol, J.-S. Thermodynamic Origin of Dendrite Growth in Metal Anode Batteries. Energy Environ. Sci. 2020. https://doi.org/10.1039/d0ee02665d.

(35) Reiss, H. The Fermi Level and the Redox Potential. J. Phys. Chem. 1985, 89 (18), 3783-3791. https://doi.org/10.1021/j100264a005.

(36) Rossmeisl, J.; Nørskov, J. K.; Taylor, C. D.; Janik, M. J.; Neurock, M. Calculated Phase Diagrams for the Electrochemical Oxidation and Reduction of Water over Pt(111). J. Phys. Chem. B 2006, 110 (43), 21833-21839. https://doi.org/10.1021/jp0631735.

(37) Rajput, N. N.; Qu, X.; Sa, N.; Burrell, A. K.; Persson, K. A. The Coupling between Stability and Ion Pair Formation in Magnesium Electrolytes from First-Principles Quantum Mechanics and Classical Molecular Dynamics. J. Am. Chem. Soc. 2015, 137 (9), 3411-3420. https://doi.org/10.1021/jacs.5b01004.

(38) Self, J.; Hahn, N. T.; Fong, K. D.; Mcclary, S. A.; Zavadil, K. R.; Persson, K. A. Ion Pairing and Redissociaton in Low-Permittivity Electrolytes for Multivalent Battery Applications. J. Phys. Chem. Lett. 2020, 11, 2046-2052. https://doi.org/10.1021/acs.jpclett.0c00334.

(39) Kubisiak, P.; Eilmes, A. Solvation of $\mathrm{Mg}^{2+}$ Ion in $\mathrm{Mg}(\mathrm{TFSI})_{2} /$ Dimethoxyethane Electrolytes - A 
View from Molecular Dynamics Simulations. J. Phys. Chem. C 2018, 122 (24), 12615-12622. https://doi.org/10.1021/acs.jpcc.8b02460.

(40) Shao, Y.; Liu, T.; Li, G.; Gu, M.; Nie, Z.; Engelhard, M.; Xiao, J.; Lv, D. Coordination Chemistry in Magnesium Battery Electrolytes: How Ligands Affect. Sci. Rep. 2013, 3, 1-7. https://doi.org/10.1038/srep03130.

(41) Lobkovskii, E. B.; Titov, L. V.; Psikha, S. B.; Antipin, Y. M.; Struchkov, Y. T. X-Ray Crystallographic Investigation of Crystals of Bis(Tetrahydroborato) Tris(Tetrahydrofuranato) Magnesium. J. Struct. Chem. 1983, 23 (4), 172-174.

(42) Lapidus, S. H.; Rajput, N. N.; Qu, X.; Chapman, K. W.; Persson, K. A.; Chupas, P. J. Solvation Structure and Energetics of Electrolytes for Multivalent Energy Storage. Phys. Chem. Chem. Phys. 2014, 16 (40), 21941-21945. https://doi.org/10.1039/c4cp03015j.

(43) Pour, N.; Gofer, Y.; Major, D. T.; Aurbach, D. Structural Analysis of Electrolyte Solutions for Rechargeable Mg Batteries by Stereoscopic Means and DFT Calculations. J. Am. Chem. Soc. 2011, 133 (16), 6270-6278. https://doi.org/10.1021/ja1098512.

(44) Mizrahi, O.; Amir, N.; Pollak, E.; Chusid, O.; Marks, V.; Gottlieb, H.; Larush, L.; Zinigrad, E.; Aurbach, D. Electrolyte Solutions with a Wide Electrochemical Window for Rechargeable Magnesium Batteries. J. Electrochem. Soc. 2008, 155, 103-109. https://doi.org/10.1149/1.2806175.

(45) Kang, S.-J.; Lim, S.; Kim, H.; Heo, J. W.; Hwang, S.; Jang, M.; Yang, D.; Hong, S.-T.; Lee, H. NonGrignard and Lewis Acid-Free Sulfone Electrolytes for Rechargeable Magnesium Batteries. Chem. Mater. 2017, 29, 3174-3188. https://doi.org/10.1021/acs.chemmater.7b00248.

(46) Liao, C.; Guo, B.; Jiang, D.; Custelcean, R.; Mahurin, S. M.; Sun, X.; Dai, S. Highly Soluble Alkoxide Magnesium Slats for Rechargeable Magnesium Batteries. J. Mater. Chem. A Mater. energy Sustain. 2014, 2, 581-584. https://doi.org/10.1039/c3ta13691d.

(47) Rajput, N. N.; Seguin, T. J.; Wood, B. M.; Qu, X.; Persson, K. A. Elucidating Solvation Structures for Rational Design of Multivalent Electrolytes - A Review; Springer International Publishing, 2018; Vol. 376. https://doi.org/10.1007/s41061-018-0195-2.

(48) Cheng, Y.; Stolley, R. M.; Han, K. S.; Shao, Y.; Arey, B. W.; Washton, N. M.; Mueller, K. T.; Helm, M. L.; Sprenkle, V. L.; Liu, J.; Li, G. Highly Active Electrolytes for Rechargeable Mg Batteries Based on [Mg2( $\mu-\mathrm{Cl}) 2] 2+$ Cation Complex in Dimethoxyethane Yingwen. Phys. Chem. Chem. Phys. 2015, 17, 13307-13314. https://doi.org/10.1039/C5CP00859J.

(49) Jankowski, P.; Lastra, J. M. G.; Vegge, T. Structure of Magnesium Chloride Complexes in Ethereal Systems: Computational Comparison of THF and Glymes as Solvents for Magnesium Battery Electrolytes. Batter. Supercaps 2020. https://doi.org/10.1002/batt.202000168.

(50) Lide, D. R. Handbook of Chemistry and Physics; CRC press: Cleveland, Ohio, 1977.

(51) Liu, T.; Shao, Y.; Li, G.; Gu, M.; Hu, J. A Facile Approach Using MgCl 2 to Formulate High Performance Mg 2 + Electrolytes for Rechargeable Mg Batteries †. J. Mater. Chem. A Mater. energy 
Sustain. 2014, 2 (1), 3430-3438. https://doi.org/10.1039/c3ta14825d.

(52) Hagopian, A.; Kopač, D.; Filhol, J.-S.; Kopač Lautar, A. Morphology Evolution and Dendrite Growth in Li- and Mg-Metal Batteries : A Potential Dependent Thermodynamic and Kinetic Multiscale Ab Initio Study. Electrochim. Acta 2020, 353, 136493. https://doi.org/10.1016/j.electacta.2020.136493.

(53) Filhol, J. S.; Doublet, M. L. Conceptual Surface Electrochemistry and New Redox Descriptors. J. Phys. Chem. C 2014, 118, 19023-19031. https://doi.org/10.1021/jp502296p. 